\title{
ANÁLISE DAS CONDIÇÕES DE SEGURANÇA NOS DESLOCAMENTOS DOS USUÁRIOS DA VIA LACERDA AGOSTINHO - LINHA AZUL, MACAÉ-RJ*
}

\author{
Conrado Vidotte Plaza ${ }^{1}$ \\ ORCID: https://orcid.org/0000-0003-0640-5327
}

Gabriella Barbosa de Oliveira Lima ${ }^{2}$

ORCID: https://orcid.org/0000-0003-3776-3274

Luísa Cardoso Lima ${ }^{3}$

ORCID: https://orcid.org/0000-0002-8064-3297

Bruno Barzellay Ferreira da Costa 4

ORCID: https://orcid.org/0000-0003-0242-4205

Recebido em: 16/06/2021.

Publicado em: 30/09/2021.

\section{RESUMO}

Acidentes de trânsito causam a perda de milhões de vidas anualmente. Sendo assim, tornar as vias urbanas mais seguras para seus usuários é primordial para o desenvolvimento local, assim como para uma integração intermunicipal saudável. O presente trabalho teve por objetivo analisar as condições inseguras enfrentadas pelos usuários da via Lacerda Agostinho, a Linha Azul, localizada no município de Macaé - RJ, assim como os possíveis fatores que as influenciam. $\mathrm{O}$ objetivo proposto foi atingido por meio de uma abordagem metodológica mista, conduzida em três etapas de coleta de dados: i) registro de acidentes nesta localidade, fornecidas pela Secretaria de Mobilidade Urbana de Macaé; ii) informações provenientes de um questionário online aplicado aos usuários da via, e iii) levantamento em campo dos elementos físicos da via. Após a análise crítica dos dados levantados, conclui-se que é de extrema importância e urgência que ações preventivas e corretivas e que políticas públicas sejam elaboradas e implementadas para a região, especialmente visando a adequação da via às suas características recentes de utilização. Com este estudo, esperase apresentar elementos capazes de subsidiar discussões com as instituições responsáveis pela formulação de políticas públicas que visam promover a segurança

\footnotetext{
${ }^{1}$ Professor Assistente do Departamento de Engenharia Civil da Universidade Federal do Rio de Janeiro - UFRJ, Campus Macaé.

${ }^{2}$ Universidade Federal do Rio de Janeiro - Campus Macaé.

${ }^{3}$ Universidade Federal do Rio de Janeiro - Campus Macaé.

${ }^{4}$ Professor Adjunto do Departamento de Engenharia Civil da Universidade Federal do Rio de Janeiro - UFRJ, Campus Macaé.
}

\section{(cc) $\mathrm{EY}-\mathrm{Ha}-\mathrm{BH}$}


pública do local.

Palavras-Chave: segurança viária; acidentes de trânsito; vias de trânsito rápido; fatores de insegurança viária.

\title{
ANALYSIS OF THE SAFETY CONDITIONS IN THE DISPLACEMENT OF USERS OF VIA LACERDA AGOSTINHO - LINHA AZUL, MACAÉ-RJ
}

\begin{abstract}
Traffic accidents cause the loss of millions of lives annually. Therefore, making urban roads safer for their users is essential for local development, as well as for healthy inter-municipal integration. This study aimed to analyze the unsafe conditions faced by users of the Lacerda Agostinho highway (Linha Azul), located in the municipality of Macaé - Rio de Janeiro - Brazil, as well as the possible factors that influence them along with. The proposed objective was achieved through a mixed methodological approach, carried out in three stages of data collection: i) registration of accidents at this location, provided by the Macaé Urban Mobility Department; ii) information from an online questionnaire applied to road users, and

iii) field survey of the physical elements of the road. After a critical analysis of the collected data, it is concluded that it is extremely important and urgent that preventive and corrective actions and public policies are designed and implemented for the region, mainly aiming to adapt the highway to its recent characteristics of use. With this study, it is expected to present elements capable of subsidizing discussions with the institutions responsible for the formulation of public policies that aim to promote the public safety of the place.
\end{abstract}

Keywords: Road safety; Traffic-accidents; Urban highways; Road insecurity factors.

\section{ANÁLISIS DE LAS CONDICIONES DE SEGURIDAD EN EL DESPLAZAMIENTO DE USUARIOS DE VIA LACERDA AGOSTINHO - LINHA AZUL, MACAÉ-RJ}

\section{RESUMEN}

Los accidentes de tráfico provocan la pérdida de millones de vidas al año. Por tanto, hacer las vías urbanas más seguras para sus usuarios es fundamental para el desarrollo local, así como para una sana integración intermunicipal. Este estudio tuvo como objetivo analizar las condiciones de inseguridad que enfrentan los usuarios de la vía Lacerda Agostinho, la Linha Azul, ubicada en la ciudad de Macaé - RJ, así como los posibles factores que las influyen. El objetivo propuesto se logró mediante un enfoque metodológico mixto, realizado en tres etapas de recopilación de datos: i) registros de accidentes en este lugar, proporcionados por el Departamento de Movilidad Urbana de Macaé; ii) información de un cuestionario en línea aplicado a los usuarios de la carretera, y iii) estudio de campo de los elementos físicos de la carretera. Luego de un análisis crítico de los datos recolectados, se concluye que es de suma importancia y urgencia que se diseñen e implementen acciones preventivas y correctivas y políticas públicas para la región, especialmente orientadas a adecuar la vía a sus características de uso recientes. Con este estudio se espera presentar elementos capaces de subsidiar las discusiones con las instituciones responsables de la formulación de políticas públicas que tengan como objetivo promover la seguridad ciudadana del lugar. 
Palabras clave: carretera segura; accidentes de tráfico; rutas de tránsito rápido; factores de inseguridad vial.

\section{INTRODUÇÃO}

Segundo a Organização Mundial da Saúde (WORLD HEALTH ORGANIZATION, 2015), cerca de 1,35 milhão de pessoas morrem a cada ano no mundo em decorrência de acidentes no trânsito, dentre as quais pedestres, ciclistas e motociclistas representam mais da metade das vítimas, constituindo, assim, a principal causa de fatalidades entre crianças e jovens adultos de 5 a 29 anos. O Brasil, atualmente, lidera as estatísticas globais, figurando na $4^{a}$ posição dentre os países que mais sofrem com sinistros de trânsito, apresentando a preocupante média de 1 óbito a cada 15 minutos (SARAGIOTTO, 2020). Além da inestimável perda de vidas humanas, esses acidentes custam aos países até 5\% de seu PIB anual, o que torna a redução de mortes e feridos no trânsito uma prioridade econômica e social (UN GENERAL ASSEMBLY, 2020). No Brasil, TAMAYO (2010) estima que os prejuízos resultantes de acidentes em áreas urbanas e em rodovias equivalem a aproximadamente $1,5 \%$ do Produto Interno Bruto - PIB do país, evidenciando a alarmante conjuntura da segurança viária no Brasil e no mundo.

Tornar as vias urbanas mais seguras para seus usuários é primordial para o desenvolvimento local, assim como para uma integração intermunicipal saudável. Para isso, faz- se necessária a análise dos fatores que contribuem com estas elevadas taxas de ocorrências. Este processo possibilita a condução de um levantamento de dados eficiente e a avaliação dos riscos presentes nos sistemas viários, subsidiando os tomadores de decisão locais na formulação de políticas públicas e projetos de engenharia que proporcionem soluções eficazes para a segurança viária local.

Tendo em vista a relevância do tema, o objeto deste estudo é a Via Lacerda Agostinho, mais conhecida como Linha Azul, localizada no município de Macaé, cidade interiorana do Estado do Rio de Janeiro. A avenida em questão compõe o projeto do Arco Viário do município, exercendo importante papel tanto para a mobilidade da urbe quanto para a integração da região com importantes Polos Geradores de Viagens do Norte Fluminense. É interessante ressaltar que a partir da década de 1970, quando "escolhido como sede da base operacional da PETROBRAS para extração e produção de petróleo e gás” (RESSIGUIER, 2011), o município vivenciou um repentino processo de crescimento econômico, impulsionado pela rápida consolidação do arranjo 
produtivo relacionado a esta indústria (DIAS, 2013). Com isso, a oferta crescente de oportunidades de empregos diretos e indiretos atraiu inúmeros novos habitantes para a região (RESSIGUIER, 2011), os quais, muitas vezes, optaram por fixar residência em municípios vizinhos, tornando o "fenômeno da população flutuante um importante fator da dinâmica demográfica municipal" (DIAS, 2013). Esta conjunção de fatores, conforme ressalta Carvalho et al. (2013), "mostrou-se associada a mudanças morfológicas significativas com alteração de traçados de ruas, assim como, com a geração de novos ou intensificação dos fluxos anteriores de carros e transportes de carga", sobrecarregando as vias urbanas, especialmente, em horários de pico.

No caso da Linha Azul, observou-se, ao longo dos anos, um crescimento acentuado da exploração imobiliária nos bairros que a tangenciam, incentivado a partir dos zoneamentos definidos no Plano Diretor Municipal de Macaé. Como consequência, definiu-se a via como um importante eixo para o desenvolvimento do município, a qual, em conjunto com os lotes adjacentes à RJ-168 e à Linha Verde, compõe o denominado Setor Viário Estrutural, destinado a instalação de empreendimentos de grande porte (SAYD; BRITTO, 2016). Por consequência, a partir de uma concepção estratégica, a via foi definida a partir de características geométricas e operacionais específicas de Via de Trânsito Rápido, caracterizadas por permitir tráfego livre para veículos em detrimento dos demais meios de transportes, amplificando os riscos para a população que movimenta-se diariamente por ela.

Neste contexto, o presente trabalho teve por objetivo analisar os aspectos que afetam a segurança dos usuários da via Lacerda Agostinho, a Linha Azul, localizada no município de Macaé - RJ. Para isso, as condições de segurança foram avaliadas a partir de: i) informações registradas de acidentes nesta localidade, fornecidas pela Secretaria de Mobilidade Urbana de Macaé; ii) informações provenientes de um questionário aplicado aos usuários e; iii) levantamento em campo dos elementos físicos da via. Os resultados desta investigação são de grande interesse não só para acadêmicos e pesquisadores, mas, especialmente, para o Poder Público Municipal, que precisa definir procedimentos criteriosos e contínuos que assegurem boas condições de deslocamento para os usuários desta via, a qual se caracteriza como uma das mais relevantes da cidade.

Após esta breve introdução ao tema, a pesquisa encontra-se estruturada em quatro seções adicionais. A seção 2 apresenta o referencial teórico do trabalho, elaborado com base na 
bibliografia disponível. A seção 3 descreve o procedimento metodológico aplicado ao estudo, uma vez que este se utiliza de três fontes de dados. A seção 4 descreve as descobertas da pesquisa e discute seus resultados. Por fim, a seção 5 resume as conclusões do estudo, assim como expõe as suas limitações e sugestões para futuras investigações.

\section{OBJETO, POLÍticas DE MOBILIDADE URBANA E FATORES DE INSEGURANÇA}

Inaugurada em 2005, a via Lacerda Agostinho, também denominada por Linha Azul, foi selecionada como objeto de estudo devido a sua importância no contexto da mobilidade urbana de Macaé e aos riscos observados à segurança dos usuários. Localizada entre a Rodovia Estadual RJ168 e a Estrada Municipal MC-01 (Estrada do Imburo), a Linha Azul possui extensão de aproximadamente 7,5 quilômetros, em pista dupla, e faz parte do projeto do Arco Viário do município (Figura 1). Quanto à mobilidade urbana, a Linha Azul apresenta papel fundamental nos deslocamentos da urbe. A sua extensão permite interligar as regiões Norte, Oeste (via RJ168) e Sul (via Linha Verde) do município de Macaé evitando-se a região central da cidade, reduzindo-se a demanda e congestionamentos na Rodovia Amaral Peixoto e no sistema viário central. Assim, a demanda com origem na BR-101 - Rodovia Governador Mário Covas, proveniente dos municípios do Rio de Janeiro e de Campos dos Goytacazes, podem acessar os bairros ao norte do município, como Aeroporto e Cabiúnas, evitando a passagem pelo Centro. Além dos deslocamentos urbanos, a Linha Azul atua como elo de ligação regional e absorve, principalmente, o fluxo de veículos pesados com destino às empresas offshore situadas nos bairros de Novo Cavaleiros e Parque de Tubos, uma vez que permite acesso da região norte para a região sul do município. Destaca-se, ainda, a proximidade da via com o aeroporto, localizado no bairro Parque Aeroporto. 
Figura 1 - Localização da Linha Azul (ponto em vermelho) e a indicação da direção dos municípios de Campos dos Goytacazes (ao norte), Rio das Ostras e Rio de Janeiro (ao sul)

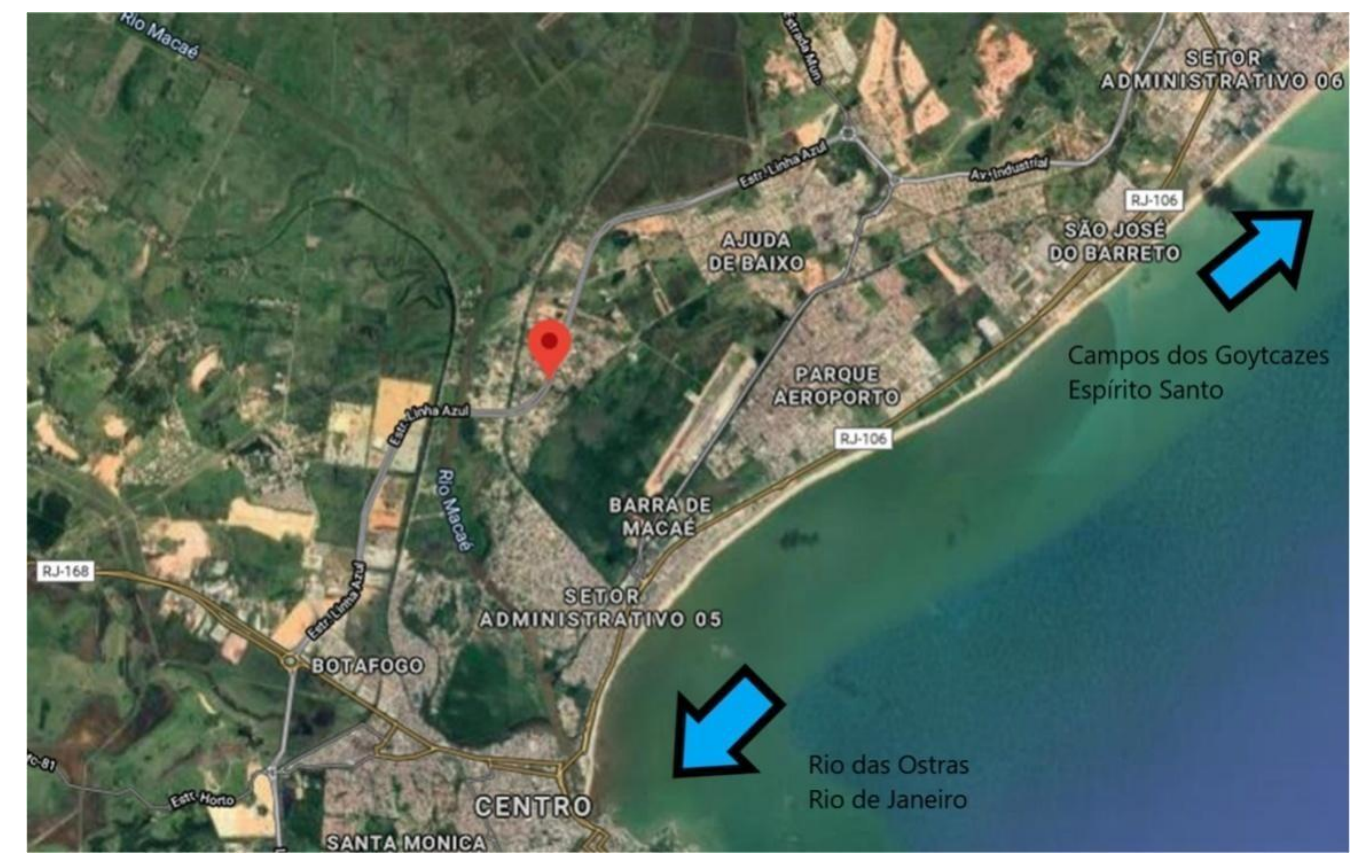

Fonte: Adaptado de Google Earth

A Lei Complementar no 076/2006 (MACAÉ, 2006), que institui o Plano Diretor do Município de Macaé - PDM, define a estruturação urbana da cidade. Em seu Anexo 3, o PDM define que a Linha Azul possui em suas adjacências zoneamentos denominados por Macroáreas de Expansão Periférica, Ocupação Prioritária e Ocupação Controlada. Para estes zoneamentos, verifica-se que a região que tangencia a via em estudo permite amplo desenvolvimento urbano, compreendendo áreas disponíveis para expansão imediata do tecido urbano, incidência de empreendimentos imobiliários de iniciativa privada, núcleos centrais de comércio e serviços, bairros residenciais em processo de transformação de uso, incentivo à promoção imobiliária para população de baixa e média renda, e áreas com concentração e predominância da atividade de serviços industriais. Estas delimitações inserem a via em estudo como um importante eixo para o desenvolvimento urbano de Macaé. Por outro lado, o PDM, em seu Art. 180, §1 $1^{\circ}$, define a Linha Azul como Via de Trânsito Rápido - VTR, caracterizadas por permitir trânsito livre para veículos, com acessos especiais e dotadas de vias auxiliares, não sendo permitidas interseções e travessia de pedestres em nível ou acessos diretos aos lotes lindeiros.

Segundo Guimarães (2012), a mobilidade urbana é a facilidade real ou efetiva das 
condições de deslocamento por qualquer modo em via pública, que leva em conta as necessidades dos habitantes. Em outras palavras, está atrelada à ligação eficaz da população aos bens e serviços locais, permitindo a realização das atividades inerentes ao dia a dia. Apesar de imprescindível, a mobilidade urbana pode vir a se tornar um privilégio, ao reprimir o deslocamento de parte dos indivíduos. Desta forma, deve ser tratada como política pública prioritária, visando promover a mitigação das ações contrárias aos deslocamentos, como, por exemplo, congestionamentos, ausência ou baixa oferta de transporte, falta de integração modal, acidentes de trânsito e até riscos de roubos e furtos.

A Lei $n^{\circ}$ 12.587, de 3 de janeiro de 2012 (BRASIL, 2012), institui as diretrizes da Política Nacional de Mobilidade Urbana - PNMU, que tem por objetivo "contribuir para o acesso universal à cidade, o fomento e a concretização das condições que contribuam para a efetivação dos princípios, objetivos e diretrizes da política de desenvolvimento urbano, por meio do planejamento e da gestão democrática do Sistema Nacional de Mobilidade Urbana" (Art. $2^{\circ}$ ). No Art. 5o, a referida lei elenca os princípios que a fundamentam. Apesar de todos serem de extrema importância e relacionarem-se entre si, destaca-se o inciso VI, que evidencia o princípio da "segurança nos deslocamentos das pessoas".

Figura 2 - Fatores que influenciam os acidentes de trânsito

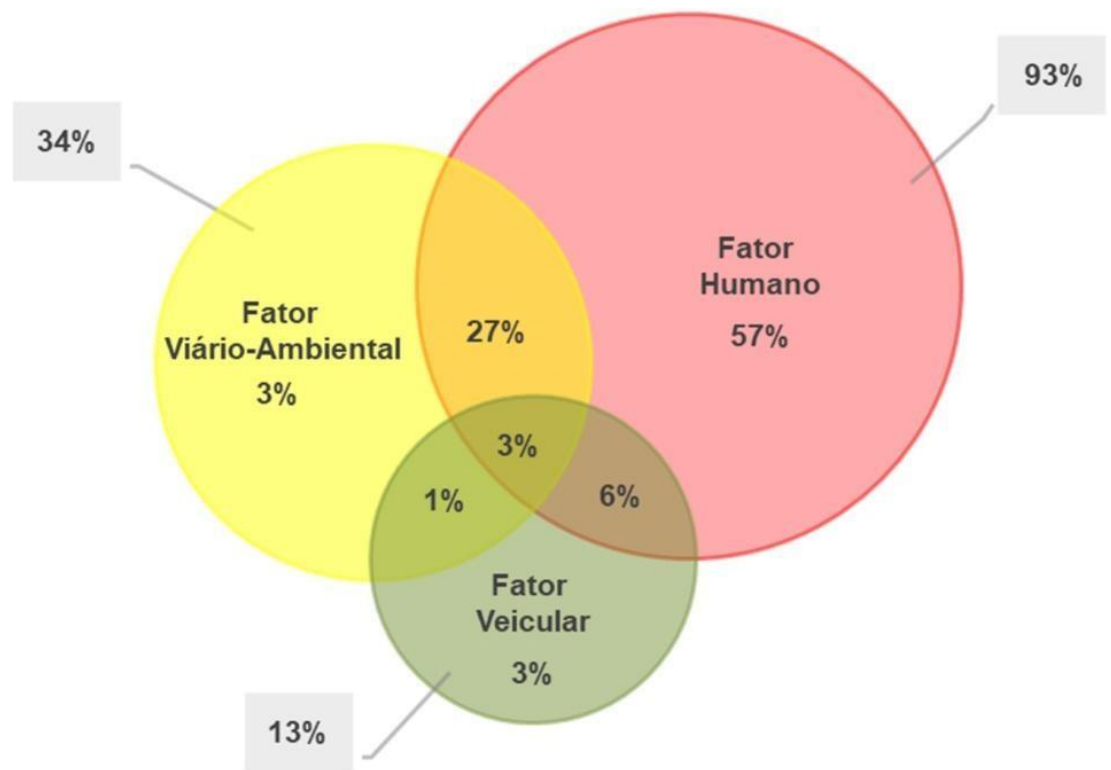

Fonte: Adaptado de (AASHTO, 2010).

De fato, a segurança é, atualmente, uma das grandes preocupações, tanto dos 
administradores dos sistemas viários, quanto da população em geral. Os acidentes de trânsito são decorrentes de uma combinação de fatores que interagem entre si, resultando no sinistro, e podem ser divididos em: Fator viário-ambiental; Fator veicular; e Fator humano. Estes se inter- relacionam de forma complexa, tornando-se difícil estimar com precisão qual deles apresenta maior ponderação na ocorrência dos acidentes. Contudo, a Figura 2 ilustra porcentagens estimadas para a ocorrência de cada um destes fatores, assim como o percentual de associação de mais de um fator. Ou seja, estima-se que 57\% dos acidentes são devidos somente a fatores humanos. Todavia, cerca de $93 \%$ de todos os acidentes são resultado de uma combinação do fator humano e outros fatores (AASHTO, 2010).

O fator humano é o que possui porcentagem mais elevada de ocorrência. Sinay e Tamayo (2005), afirmam que isso ocorre uma vez que todos os elementos atuam influenciando e sobrecarregando o fator humano. Campos (1978) faz uma análise crítica de como as características e funções inerentes aos motoristas influenciam na tomada de decisão. Dentre os riscos associados aos fatores humanos, destacam-se o consumo de bebidas alcoólicas, a falta de atenção dos motoristas, a circulação na contramão e velocidades não compatíveis com a via. Quanto à atenção dos motoristas, Hoffmann (2005) descreve que os condutores não processam a informação essencial e não agem coerentemente sobre ela, mesmo quando os registros oculares mostram que a fixação dos olhos nos estímulos visuais realmente ocorreu. Em segundo lugar, destacam-se os fatores viário-ambientais, os quais abrangem as condições da via e fatores climáticos. Dentre eles, listam-se: geometria e traçado da pista, disposição do pavimento, sinalização mal colocada, chuvas, neblina e demais condições climáticas. Por último, o fator veicular, que comumente pode ser evitado com manutenções preventivas e preditivas, já que inclui problemas como falhas mecânicas, peças sem conservação, idade dos veículos e mau uso. Neste ponto, já se observa a importância estrutural da Linha Azul, e, também, a necessidade de revisão das políticas operacionais e de projeto de infraestrutura e operação da via. Sendo assim, além de sua importância para a logística e mobilidade urbana, a Linha azul foi selecionada como objeto de estudo devido aos riscos à segurança constatados pela elevada quantidade de acidentes ocorridos nos últimos anos. 


\section{METODOLOGIA}

Esta seção apresenta a metodologia de pesquisa utilizada neste artigo, que teve como objetivo analisar as inseguranças enfrentadas pelos usuários da via Lacerda Agostinho, a Linha Azul, localizada no município de Macaé - RJ. O presente estudo adotou uma abordagem metodológica mista e foi conduzida em três etapas de coleta de dados (Figura 3), as quais combinam métodos quantitativos e qualitativos de forma a incrementar a confiabilidade de seu resultado (RENUKAPPA et al., 2016; RUPARATHNA e HEWAGE, 2015). Após a realização de revisão bibliográfica visando a fundamentação teórica da pesquisa, seguiu-se a primeira etapa de obtenção e análise de dados, que consistiu na verificação do registro de acidentes ao longo da Linha Azul no período de janeiro de 2019 a setembro de 2019, fornecido pela Secretaria de Mobilidade Urbana de Macaé.

Figura 3 - Abordagem metodológica da pesquisa

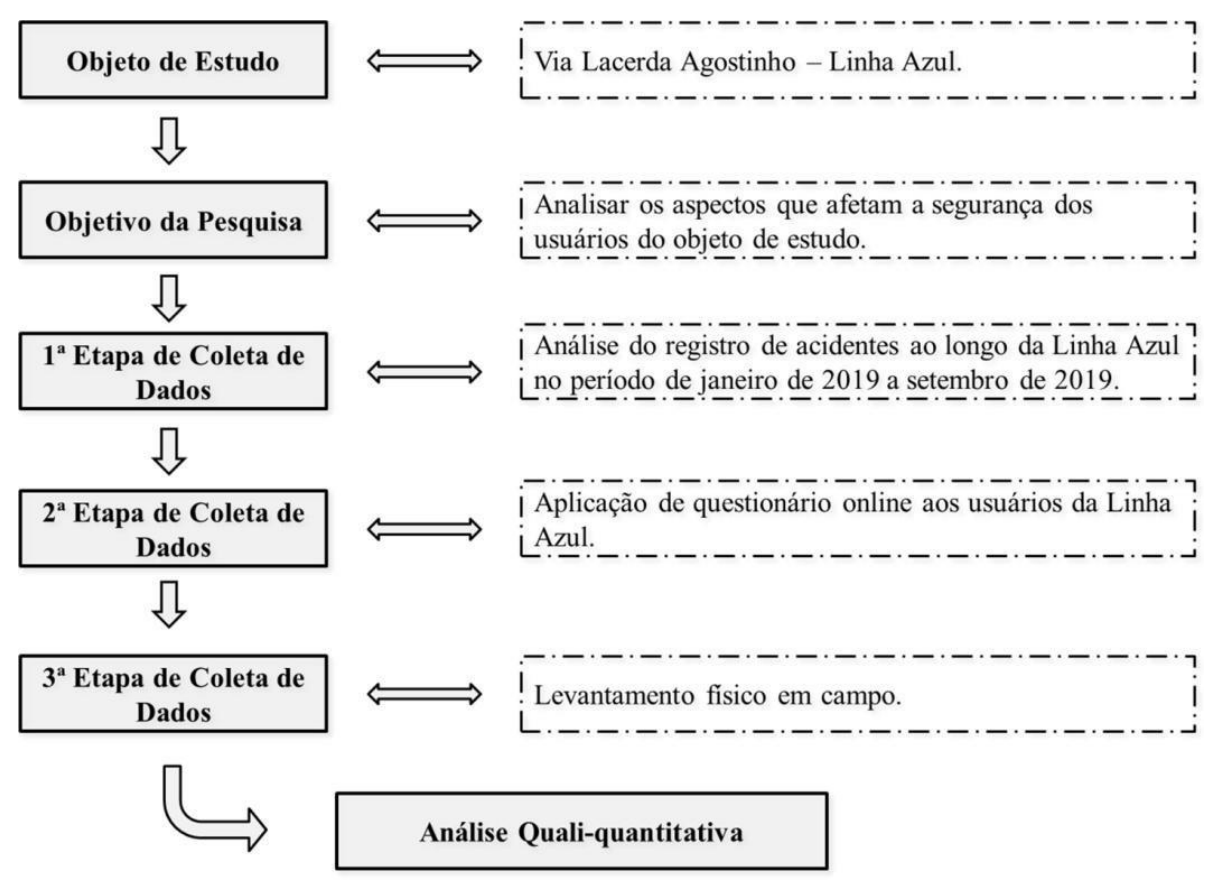

Fonte: Elaborado pelos autores.

A segunda etapa foi realizada na forma de um questionário online com doze questões administrado diretamente pelos autores para uma amostra de 52 usuários da via em estudo 
(Tabela 1). Esta ferramenta de coleta de dados é frequentemente utilizada para obter a opinião de um grupo de pessoas a respeito de um tema em específico (RUPARATHNA e HEWAGE, 2015). Uma vez que esta pesquisa foi realizada durante o período da epidemia mundial da COVID-19, a aplicação de uma pesquisa online foi considerada adequada, pois permitiu a sua realização em conformidade com todos os protocolos de segurança necessários. Por outro lado, este aspecto limitou a quantidade de respostas obtidas, a qual certamente seria superior caso a pesquisa houvesse sido realizada de forma presencial no local de estudo.

Tabela 1 - Informações básicas do questionário online

\begin{tabular}{ll}
\hline Universo & Usuários da Via Lacerda Agostinho - Linha Azul \\
\hline Escopo & Aspectos que influenciam a segurança dos usuários da via \\
\hline Estratégia de amostragem & Amostragem aleatória proposital \\
\hline Tipo de questionário & Questionário estruturado realizado por e-mail \\
\hline Idioma do questionário & Português \\
\hline Tamanho da amostra & 52 questionários válidos \\
\hline Período de aplicação do questionário & $20 / 11 / 2020$ à 20/01/2021 \\
\hline
\end{tabular}

Fonte: Elaborado pelos autores.

Por fim, foi realizado levantamento físico em campo, o qual buscou confirmar a correlação entre a percepção dos usuários acerca da segurança na via em estudo com os acidentes registrados na mesma, de forma a possibilitar a compreensão dos fatores que preocupam seus usuários durante os deslocamentos ao longo do trecho. As inspeções foram realizadas em duas ocasiões, a primeira no dia 17/10/2020 e a segunda no dia 22/03/2021. Os resultados obtidos por meio das ferramentas de coleta de dados empregadas são apresentados na Seção 4 deste artigo.

\section{RESULTADOS E DISCUSSÕES}

\subsection{Análise dos Registros de Acidentes}

A seguinte análise foi realizada com base no Relatório de Acidentes com Vítimas Fatais e Não Fatais na Linha Azul, para o período compreendido entre janeiro de 2019 e setembro de 2020, obtido junto a Secretaria de Mobilidade Urbana do Município de Macaé. O documento apresenta, para cada ocorrência registrada, as informações de data, hora, bairro, condição da sinalização no local, se há cruzamento, tipo de acidente, número de veículos envolvidos, número de vítimas e severidade (Tabela 2). 
Tabela 2 - Relatório de acidentes com vítimas fatais e não fatais no período de janeiro de 2019 a setembro de 2020.

\begin{tabular}{|c|c|c|c|c|c|c|c|c|}
\hline Tipo de & & & & & & $\mathrm{N}^{\circ} \mathrm{de}$ & $\mathrm{N}^{0} \mathrm{de}$ & \\
\hline Data & Hora & Bairro & $\begin{array}{l}\text { Sinalizaç } \\
\text { ão }\end{array}$ & Cruzamento & $\begin{array}{l}\text { Acide } \\
\text { nte }\end{array}$ & $\begin{array}{l}\text { Veículo } \\
\mathbf{S}\end{array}$ & $\begin{array}{l}\text { Vítima } \\
\text { s }\end{array}$ & $\begin{array}{l}\text { Severida } \\
\text { de }\end{array}$ \\
\hline $12 / 01 / 2019$ & $18: 20$ & $\begin{array}{l}\text { Barra de } \\
\text { Macaé }\end{array}$ & B & Não & $\mathrm{COF}$ & 1 & 0 & SV \\
\hline $16 / 01 / 2019$ & $07: 40$ & $\mathrm{NC}$ & B & Não & $\mathrm{C} / \mathrm{A}$ & 2 & 1 & VNF \\
\hline $21 / 07 / 2019$ & $06: 40$ & $\begin{array}{l}\text { Virgem } \\
\text { Santa }\end{array}$ & $\mathrm{NC}$ & $\mathrm{NÃO}$ & $\mathrm{T} / \mathrm{C}$ & 1 & 0 & SV \\
\hline $02 / 07 / 2019$ & $16: 51$ & $\begin{array}{l}\text { Virgem } \\
\text { Santa }\end{array}$ & $\mathrm{NC}$ & $\mathrm{NÃO}$ & $\mathrm{C} / \mathrm{A}$ & 2 & 0 & SV \\
\hline $11 / 04 / 2019$ & $17: 50$ & $\begin{array}{c}\text { Ajuda de } \\
\text { Baixo }\end{array}$ & B & NÃO & $\mathrm{NC}$ & 2 & 1 & VNF \\
\hline $26 / 05 / 2019$ & $\mathrm{NC}$ & $\begin{array}{c}\text { Ajuda de } \\
\text { Baixo }\end{array}$ & B & NÃO & $\mathrm{C} / \mathrm{A}$ & 2 & 1 & VNF \\
\hline $29 / 05 / 2019$ & 07:00 & $\begin{array}{l}\text { Barra de } \\
\text { Macaé }\end{array}$ & I & NÃO & $\mathrm{C} / \mathrm{A}$ & 2 & 2 & VNF \\
\hline 05/07/2019 & $\mathrm{NC}$ & $\begin{array}{l}\text { Barra de } \\
\text { Macaé }\end{array}$ & B & NÃO & $\mathrm{C} / \mathrm{A}$ & 2 & 2 & VNF \\
\hline 10/07/2019 & $07: 55$ & $\begin{array}{l}\text { Barra de } \\
\text { Macaé }\end{array}$ & B & NÃO & C/A & 2 & 1 & VNF \\
\hline $14 / 07 / 2019$ & $16: 40$ & $\begin{array}{l}\text { Barra de } \\
\text { Macaé }\end{array}$ & I & NÃO & $\mathrm{AP}$ & 1 & 1 & VNF \\
\hline $20 / 07 / 2019$ & $14: 45$ & $\begin{array}{l}\text { Virgem } \\
\text { Santa }\end{array}$ & B & NÃO & $\mathrm{T} / \mathrm{C}$ & 1 & 1 & VNF \\
\hline $24 / 07 / 2019$ & $19: 30$ & $\mathrm{NC}$ & I & $\mathrm{NC}$ & $\mathrm{COF}$ & 1 & 1 & VNF \\
\hline 18/09/2019 & $16: 10$ & $\begin{array}{l}\text { Virgem } \\
\text { Santa }\end{array}$ & $\mathrm{NC}$ & NÃO & $\mathrm{C} / \mathrm{A}$ & 2 & 0 & SV \\
\hline $28 / 09 / 2019$ & $21: 45$ & $\begin{array}{l}\text { Barra de } \\
\text { Macaé }\end{array}$ & B & $\mathrm{NC}$ & $\mathrm{COF}$ & 2 & 2 & VNF \\
\hline $28 / 08 / 2019$ & $14: 30$ & $\begin{array}{l}\text { Ajuda de } \\
\text { Cima }\end{array}$ & B & SIM & $\mathrm{C} / \mathrm{A}$ & 2 & 1 & VNF \\
\hline $12 / 09 / 2019$ & $17: 50$ & $\begin{array}{l}\text { Ajuda de } \\
\text { Cima }\end{array}$ & B & NÃO & C/A & 2 & 2 & VNF \\
\hline 28/09/2019 & $00: 10$ & $\begin{array}{l}\text { Barra de } \\
\text { Macaé }\end{array}$ & B & NÃO & AP & 1 & 2 & VNF \\
\hline $06 / 10 / 2019$ & $18: 00$ & $\mathrm{NC}$ & $\mathrm{NC}$ & $\mathrm{NC}$ & $\mathrm{NC}$ & 2 & 4 & VNF \\
\hline $17 / 10 / 2019$ & 08:00 & $\begin{array}{l}\text { Virgem } \\
\text { Santa }\end{array}$ & D & NÃO & $\mathrm{C} / \mathrm{A}$ & 2 & 1 & VNF \\
\hline $09 / 11 / 2019$ & $06: 50$ & $\begin{array}{l}\text { Virgem } \\
\text { Santa }\end{array}$ & B & NÃO & $\mathrm{T} / \mathrm{C}$ & 1 & 2 & VNF \\
\hline $14 / 12 / 2019$ & 06:05 & $\begin{array}{l}\text { Barra de } \\
\text { Macaé }\end{array}$ & $\mathrm{NC}$ & NÃO & $\mathrm{COF}$ & 2 & 0 & SV \\
\hline $04 / 12 / 2019$ & $07: 00$ & $\begin{array}{l}\text { Barra de } \\
\text { Macaé }\end{array}$ & $\mathrm{NC}$ & NÃO & AA & 1 & 0 & SV \\
\hline $18 / 01 / 2020$ & $18: 15$ & $\begin{array}{l}\text { Barra de } \\
\text { Macaé }\end{array}$ & B & $\mathrm{NC}$ & AP & 1 & 2 & VF \\
\hline
\end{tabular}




\begin{tabular}{ccccccccc}
\hline $28 / 01 / 2020$ & $19: 30$ & $\begin{array}{c}\text { Virgem } \\
\text { Santa }\end{array}$ & B & NC & C/A & 1 & 1 & VNF \\
\hline $25 / 02 / 2020$ & $02: 30$ & $\begin{array}{c}\text { Barra de } \\
\text { Macaé }\end{array}$ & B & NC & COF & 1 & 0 & SV \\
\hline $15 / 03 / 2020$ & $16: 50$ & NC & B & NÃO & C/A & 1 & 1 & VNF \\
\hline $26 / 03 / 2020$ & NC & NC & D & NÃO & T/C & 1 & 2 & VNF \\
\hline $10 / 04 / 2020$ & $13: 00$ & NC & B & NC & C/A & 2 & 1 & VNF \\
\hline $22 / 06 / 2020$ & NC & $\begin{array}{c}\text { Virgem } \\
\text { Santa }\end{array}$ & B & NC & C/A & 2 & 1 & VNF \\
\hline $28 / 06 / 2020$ & $11: 25$ & NC & B & NC & C/A & 2 & 2 & VNF \\
\hline $08 / 08 / 2020$ & $14: 45$ & NC & I & NC & C/A & 2 & 3 & VF \\
\hline $09 / 09 / 2020$ & $19: 30$ & NC & B & NC & C/A & 2 & 0 & SV \\
\hline
\end{tabular}

Fonte: Adaptado de Secretaria de Mobilidade Urbana de Macaé.

Notas: Sinalização: B - Boa; D - Deficiente; I - Inexistente. Tipo de Acidente: AA - Atropelamento de Animal; AP - Atropelamento de Pedestre; COF - Choque com Objeto Fixo; C/A - Colisão/Abalroamento; T/C Tombamento/Capotagem. Severidade: SV - Sem vítima; VNF - Vítima Não Fatal; VF - Vítima Fatal.

Verifica-se que dos 32 registros que constituem a base obtida, 22 ocorreram em 2019 e apenas 10 nos nove primeiros meses de 2020. De imediato, faz-se importante destacar que no primeiro trimestre de 2020 o país iniciou, de forma intensificada, o enfrentamento à pandemia do coronavírus. No caso específico de Macaé, a Prefeitura Municipal emitiu o Decreto 030/2020 no dia 16 de março de 2020, que dispõe sobre a adoção de medidas preventivas para a contenção do coronavírus no Município de Macaé, incluindo a suspensão das aulas em toda a rede de ensino pública e privada (MACAÉ, 2020). Em decretos posteriores, as atividades laborais no município também passaram a ser suspensas e controladas. A consequente redução dos deslocamentos diários, impactou diretamente nas ocorrências de acidentes. Na via em estudo, nos três primeiros meses de 2019, foram registrados apenas dois acidentes (0,67 acidentes/mês), ante cinco registros para o mesmo período de 2020 (1,67 acidentes/mês), aumento de 250\% em relação ao ano anterior. Já entre os meses de abril e setembro, após o início da pandemia, observou-se quinze registros de acidentes em 2019 (2,5 acidentes/mês) e apenas cinco para o mesmo período de 2020 (0,83 acidentes/mês), ou seja, uma redução de $66 \%$ em relação ao ano anterior. 
Figura 4 - Relação entre o número de ocorrência em cada período do dia e a gravidade dos acidentes.

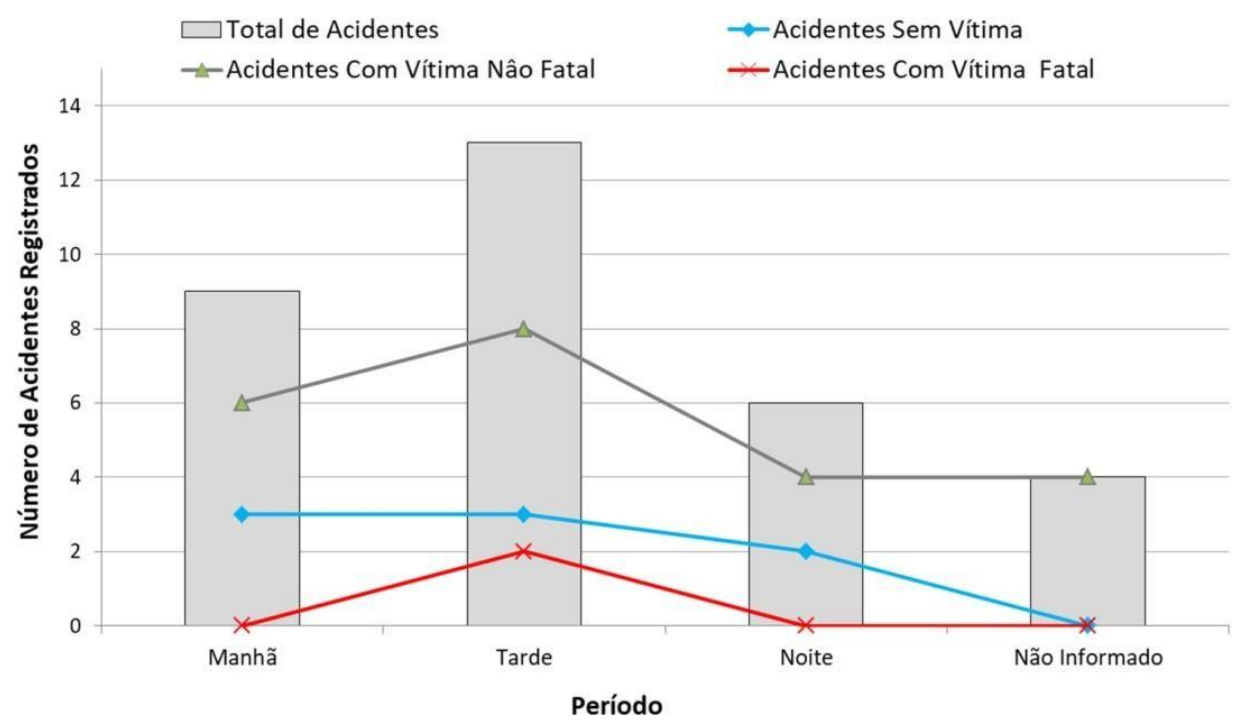

Fonte: Adaptado de Secretaria de Mobilidade Urbana de Macaé.

Com base neste relatório é possível concluir que $25 \%$ dos acidentes não tiveram vítimas, 69\% tiveram vítimas não fatais e 6\% tiveram vítimas fatais (Figura 4). Além disso, a ocorrência de acidentes se mostrou ligeiramente maior no período da tarde (12h às 19h) e menor no período da manhã (6h às 12h) e noite (19h e 6h), com, respectivamente, $41 \%, 28 \%$ e 19\% (12\% sem informação de horário registrada). O maior índice de acidentes à tarde e manhã pode estar associado ao maior volume de tráfego na via nestes horários, atrelado à boa visibilidade, à falta de fiscalização (encorajando os motoristas a aumentarem a velocidade) e a exaustão (falta de concentração dos motoristas - fator humano).

Quanto ao tipo de ocorrência, observou-se que, dos registros presentes no relatório de acidentes, 53\% correspondem à colisão/abalroamento, $16 \%$ à choque com objeto fixo, $13 \%$ à tombamento/capotagem, $9 \%$ à atropelamento de pedestre e 3\% à atropelamento de animal. Dois registros não continham a descrição do tipo de ocorrência. É importante ressaltar que as condições de sinalização nos locais de ocorrência dos acidentes foram classificadas como boas na maior parte dos registros $(62,5 \%)$. A associação do tipo de ocorrência com o período registrado, conforme ilustrado na Figura 5, comprovou que grande parte das casualidades ocorreram no período vespertino. $\mathrm{O}$ alto índice de atropelamento de pedestres, colisões e capotagens neste período pode estar relacionado ao fato desta faixa horária absorver dois ciclos de alto tráfego na 
via, quais sejam, o horário do almoço e, especialmente, o retorno do trabalho para casa após o término do expediente de trabalho. Por outro lado, percebe-se que as ocorrências de choque com objeto fixo, se concentraram no período noturno, onde a visibilidade do condutor encontra-se limitada.

Figura 5 - Distribuição dos acidentes, por tipo de ocorrência, entre os períodos da manhã (6h às 12h), da tarde (12h às 19h) e da noite (19h e 6h) segundo o Relatório de Acidentes com Vítimas Fatais e Não

Fatais na Linha Azul

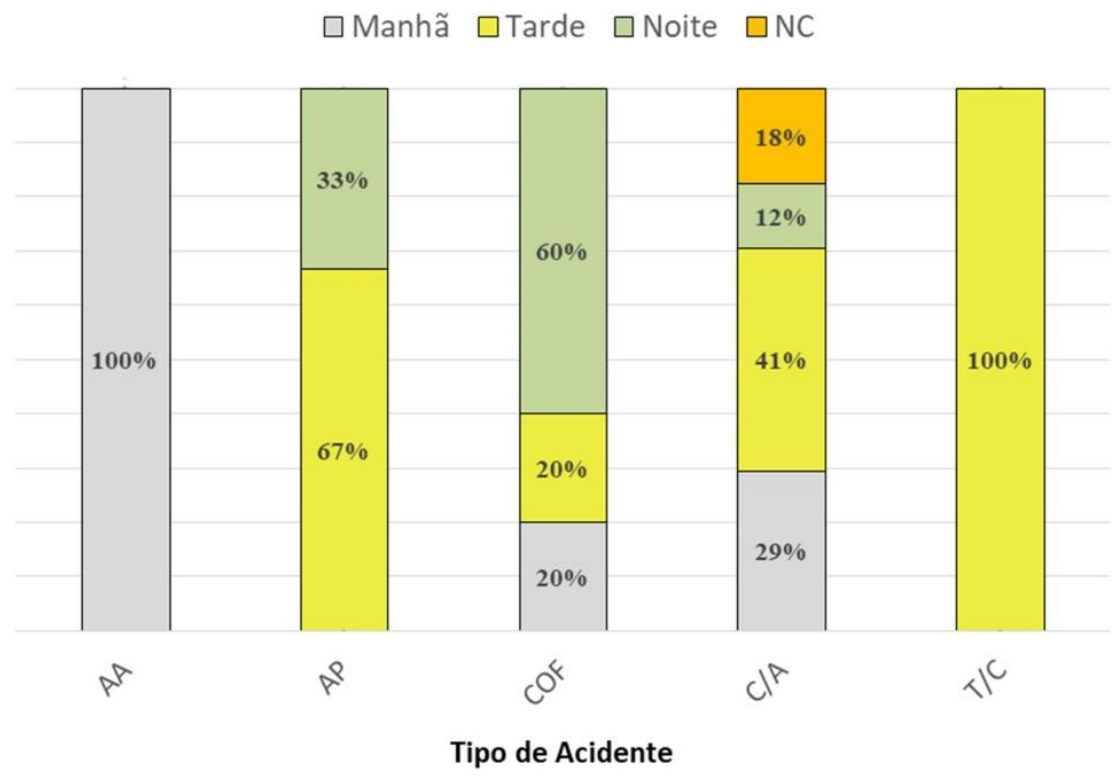

Fonte: Adaptado de Secretaria de Mobilidade Urbana de Macaé.

Notas: Tipo de Acidente: AA - Atropelamento de Animal; AP - Atropelamento de Pedestre; COF - Choque com Objeto Fixo; C/A - Colisão/Abalroamento; T/C - Tombamento/Capotagem. NC: Não Consta.

As ocorrências registradas foram localizadas geograficamente segundo os pontos de referência relatados. Estes acidentes se concentram próximos aos acessos da via (na rotatória com a RJ-168 e Linha Verde, Figura 6a, e na rotatória com a Estrada do Imburo, Figura 6b) e, principalmente, próximo às entradas dos bairros Virgem Santa e Piracema (Figura 7). Observa-se que os acidentes estão concentrados em locais com presença de Polos Geradores de Viagem, ou seja, próximo a setores comerciais e residenciais. O trecho com maior quantidade de registros de acidentes está adjacente ao bairro Piracema. 
Figura 6 - Localização dos registros de acidentes na Linha Azul (a) próximo à rotatória com a RJ168 e Linha Verde; (b) próximo à rotatória com a Estrada do Imburo

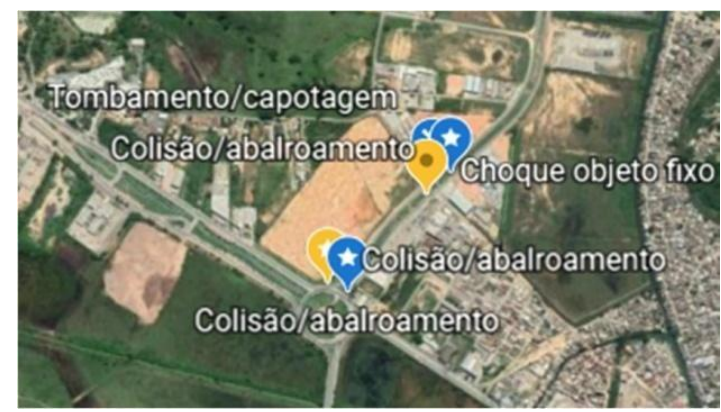

(a)

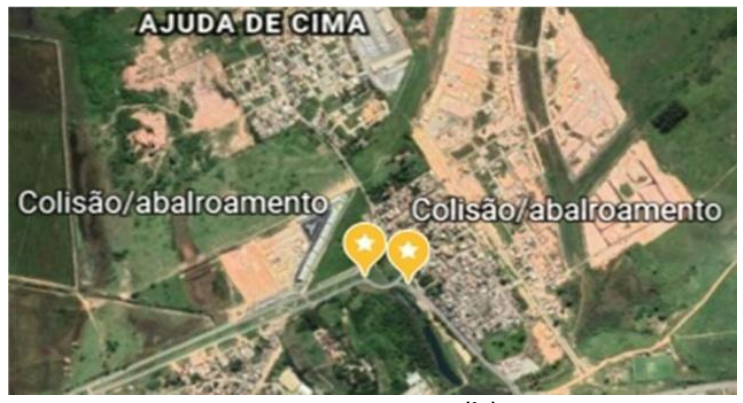

(b)

Fonte: Adaptado de Google Earth.

Figura 7 - Localização dos registros de acidentes na Linha Azul: próximo à entrada dos bairros Virgem Santa e Piracema

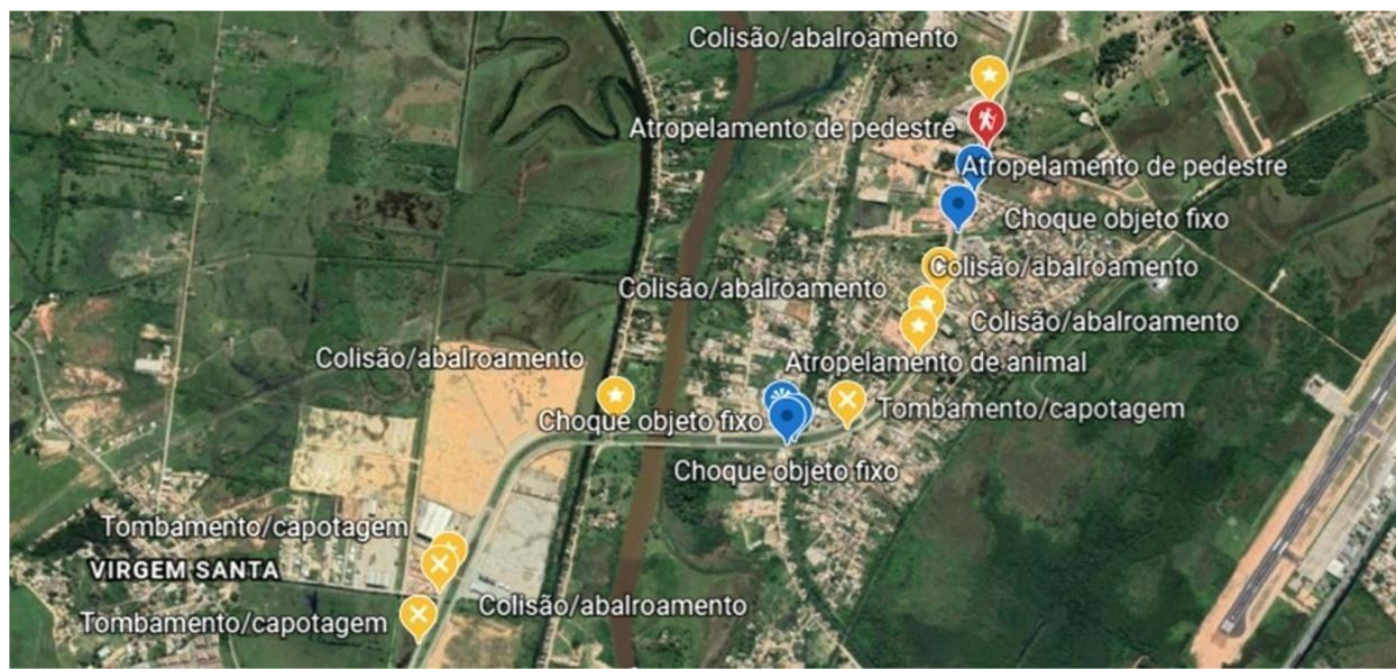

Fonte: Adaptado de Google Earth.

\subsection{Análise do questionário online}

Visando coletar a opinião da população sobre os principais problemas encontrados na Linha Azul, elaborou-se um formulário online através da plataforma Google Forms. Assim, foi possível atingir os usuários de forma remota, respeitando as medidas preventivas de controle e combate ao coronavírus. O link da pesquisa foi divulgado em diferentes meios de comunicação, dentre eles, destacam-se as redes sociais da $15^{\mathrm{a}}$ Subseção da OAB-RJ, grupos de WhatsApp e em entrevista à Rádio FM 101 no dia 03/12/2020.

O questionário foi estruturado em duas etapas. A primeira teve por objetivo limitar sua 
aplicação apenas aos usuários da via. Desta forma, na primeira questão o entrevistado devia indicar se utiliza a Linha Azul e com qual frequência. Caso ele não fosse um usuário da via em estudo, o formulário se encerrava. Caso contrário, o respondente era direcionado à segunda etapa, constituída por doze perguntas visando a caracterização do usuário e sua percepção quanto à avaliação da segurança na via a partir de diversos aspectos. Obteve-se respostas de 56 pessoas, das quais, apenas 4 (7\%) não utilizavam a Linha Azul. Ou seja, no final do período de coleta foram obtidos 52 questionários válidos. Dentre os participantes, conforme apontado na Tabela 3, apenas $21 \%$ indicaram que residem próximo à via, reforçando a sua caraterística de importante corredor de acesso para outras localidades da cidade. Além disso, apenas três se classificaram como portadores de mobilidade reduzida. Outra informação relevante para a pesquisa é a alta frequência de participantes que alegaram utilizar a via somente algumas vezes por mês (quase nunca), o que pode prejudicar a sua avaliação quanto ao objeto de estudo. Contudo, somando-se os demais respondentes, inferimos que trinta afirmaram trafegar pelo trecho ao menos entre uma e quatro vezes na semana, ampliando assim a confiabilidade dos dados obtidos.

Tabela 3 - Resumo das respostas às questões iniciais do questionário

\begin{tabular}{|c|c|c|c|c|c|c|}
\hline $\begin{array}{c}\text { D } \\
\text { at } \\
\mathbf{a}\end{array}$ & SIM & NÃOO & $\begin{array}{c}\text { Sem } \\
\text { pre }\end{array}$ & $\begin{array}{l}\text { Quase } \\
\text { Sempr } \\
\text { e }\end{array}$ & $\begin{array}{c}\text { Às } \\
\text { Vezes }\end{array}$ & $\begin{array}{l}\text { Quase } \\
\text { Nunca }\end{array}$ \\
\hline Reside próximo à via? & $21 \%$ & $79 \%$ & ----- & ---- & ---- & ---- \\
\hline Apresenta mobilidade reduzida? & $6 \%$ & $94 \%$ & ----- & ---- & ----- & ----- \\
\hline Com que frequência utiliza a via? & ----- & ----- & $\begin{array}{c}21,15 \\
\%\end{array}$ & $\begin{array}{c}15,3 \\
8 \%\end{array}$ & $\begin{array}{c}21,15 \\
\%\end{array}$ & $\begin{array}{c}42,3 \\
2 \%\end{array}$ \\
\hline
\end{tabular}

Fonte: Elaborado pelos autores.

A questão seguinte procurou aferir os meios de transporte que os participantes da pesquisa costumam utilizar na Linha Azul. Nesta questão, bem como nas que a seguem, foi permitido ao participante selecionar mais de uma opção. Pode-se perceber, conforme ilustra a Figura 8a, que o emprego do carro é bastante expressivo, constituindo a maior parcela do fluxo de veículos na via. Dentre os 52 entrevistados, 47 alegaram fazer uso deste modal, justificando assim o alto índice de colisões/abalroamentos que ocorreram durante o período investigado. Considerando os 32 registros obtidos, mais da metade se deu em função deste tipo de acidente. Vale ressaltar que em visita dos autores ao local, foram constatados, ainda, veículos com tração animal, não abordados 
no questionário.

É válido comparar o perfil dos modais utilizados com a percepção dos usuários quanto a quantidade de locais de travessia segura ao longo da via para os pedestres a atravessarem de um lado ao outro (Figura 8b). Ao serem questionados, 94\% dos participantes concordaram que não existem travessias suficientes ao longo do trecho de 7,5 $\mathrm{km}$ estudados e mais da metade alegou que os veículos não respeitam a travessia, ou seja, não param e nem reduzem a velocidade ao se aproximar. Esta é uma informação interessante, visto que, segundo a Figura 8a, somente 3 participantes informaram que utilizam a Linha Azul como pedestres. Sendo assim, os próprios entrevistados constataram, na condição de condutores ou passageiros, que os veículos automotores, em geral, tendem a não respeitar a legislação vigente. Esta deficiência agrava os riscos aos pedestres na via e realça a necessidade de infraestruturas adequadas aos transportes ativos.

Figura 8 - (a) Divisão dos usuários de acordo com meio de transporte utilizado. (b) Percepção dos usuários quanto a quantidade de locais de travessia segura na via.

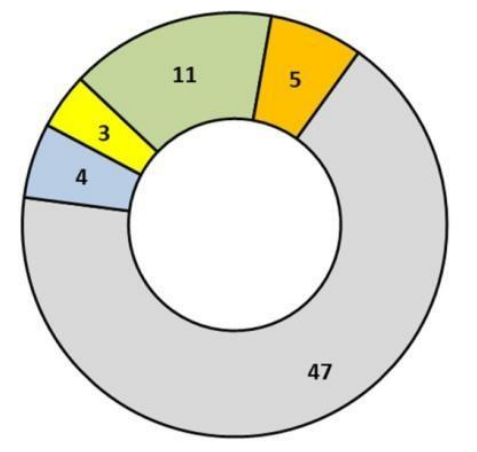

(a)

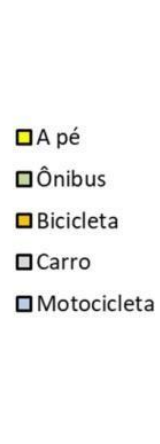

Fonte: Elaborado pelos autores.

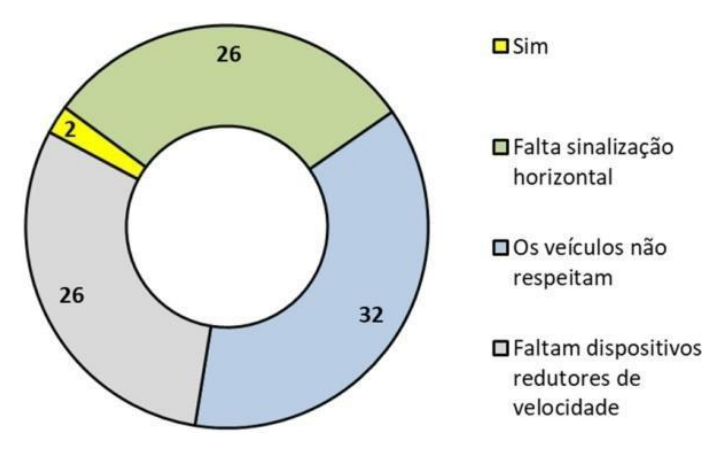

(b)

A opinião dos usuários quanto à existência de fatores que aumentam o potencial de ocorrência de acidentes na via foi verificada (Figura 9) e dos 52 usuários participantes da pesquisa, apenas $4 \%$ responderam que não existem fatores que aumentam o potencial de risco, em oposição aos demais, que assinalaram uma ou mais opções. Observa-se assim, que três fatores foram responsáveis por metade das reclamações dos entrevistados. Salienta-se a alta frequência 
de respostas auferidas pela primeira colocada deste ranking, o acúmulo de água de chuva na pista, a qual foi assinalada por $82,7 \%$ dos entrevistados. Este resultado coloca em evidência a fragilidade crônica do munícipio no que diz respeito ao seu sistema de drenagem. A presença de água na faixa de rodagem pode indicar tanto a ineficiência dos dispositivos de drenagem, seja por mal dimensionamento ou ausência de manutenção preventiva e corretiva, quanto insuficientes inclinações transversais e/ou longitudinais na via para escoamento das águas pluviais. Em ambos os casos, geram-se riscos elevados àqueles que transitam na região em dias de chuva.

Figura 9 - Divisão dos usuários de acordo com a opinião sobre fatores que influenciam em acidentes

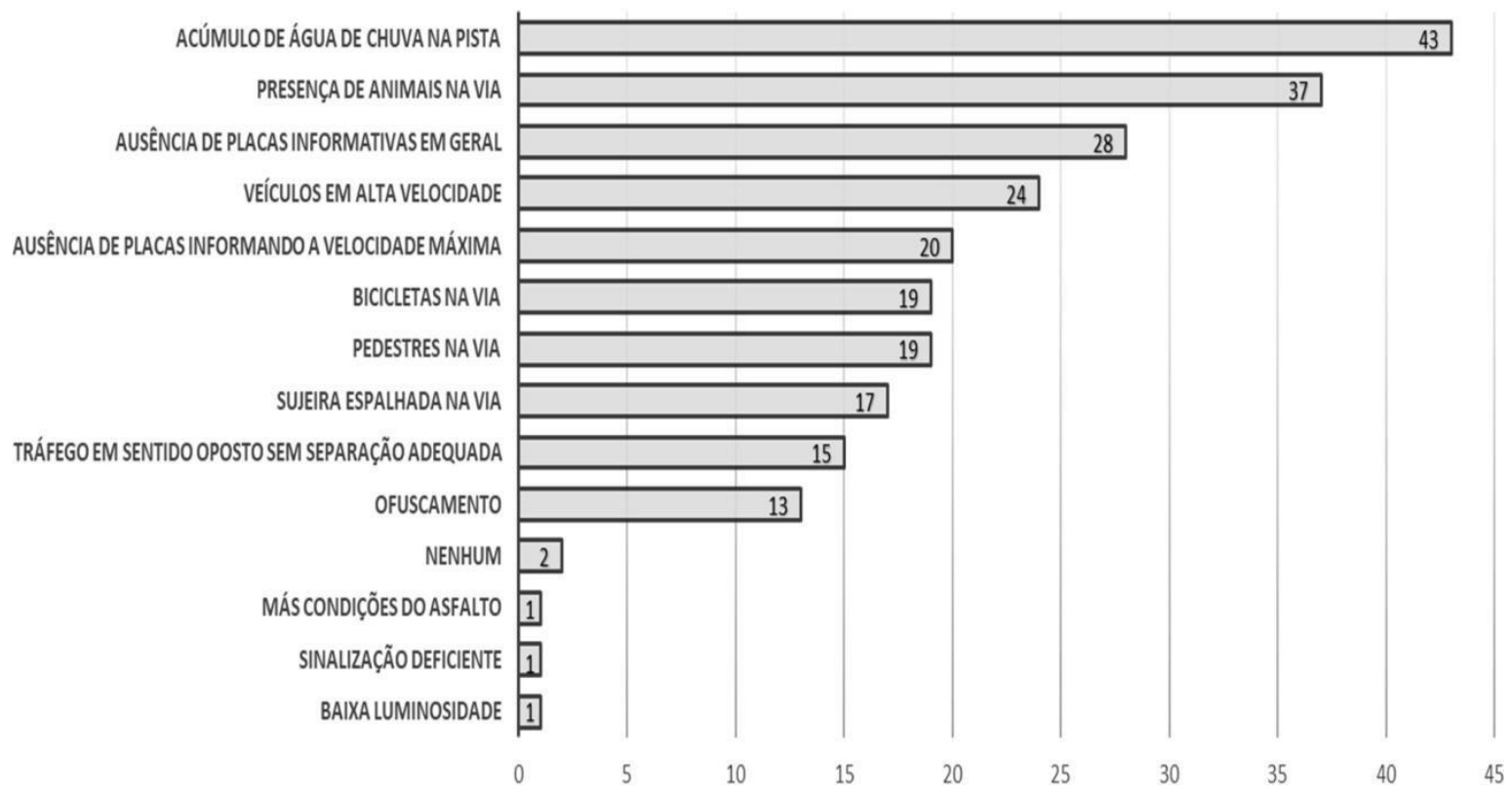

Fonte: Elaborado pelos autores.

Apesar de apenas 24 respondentes haverem apontado os veículos transitando em alta velocidade como um fator que influencia em acidentes na via, e o item "ausência de placas informando a velocidade máxima" ter sido assinalado por apenas 20 usuários (Figura 9), ao serem questionados se em sua opinião a velocidade regulamentada na via é respeitada pelos veículos, apenas $10 \%$ dos entrevistados responderam que "sempre" sentem que o limite de velocidade é respeitado. As maiores parcelas de respostas à esta indagação se concentraram em "quase nunca" $(42,3 \%)$ e "às vezes" (25\%). Esta é uma conclusão preocupante, visto que os limites de velocidade são definidos para a operação segura da via, baseadas nas definições 
geométricas e distâncias de visibilidade e frenagem, por exemplo. Desta forma, o não cumprimento da velocidade pode ocasionar situações de riscos, como no tempo de resposta e distância de parada insuficientes caso um animal ou pedestre apareça.

Quanto à sensação de insegurança vivenciada pelos usuários ao trafegar pela Linha Azul, 75\% assinalaram que à noite a sensação de insegurança é maior, e 63\% acham a via insegura, mas nunca estiveram em situação de risco. Estas são frequências altas se comparadas à quantidade de entrevistados que relataram efetivamente terem sido assaltados na via (4\%). Esta sensação de insegurança possivelmente está relacionada às condições de iluminação da mesma durante o período noturno. Conforme se pode observar na Figura 10, em média, 45\% dos participantes apontaram que a iluminação do trecho em questão é insuficiente em toda a sua extensão, especialmente em locais onde o condutor se vê obrigado a reduzir a velocidade, tais como: cruzamentos, retornos, curvas acentuadas, passagens de pedestres, estreitamentos de pista (pontes) e junto à regiões que tendem a acumular água da chuva. A Figura 10 também ilustra que 58\% dos entrevistados julgam que a sinalização de advertência e regulamentação ao longo da via não são adequadas, especialmente nas curvas (42\%), consideradas trechos de alto risco para colisões, capotamentos e atropelamentos.

Figura 10 - Opinião sobre sinalização vertical e iluminação na via.

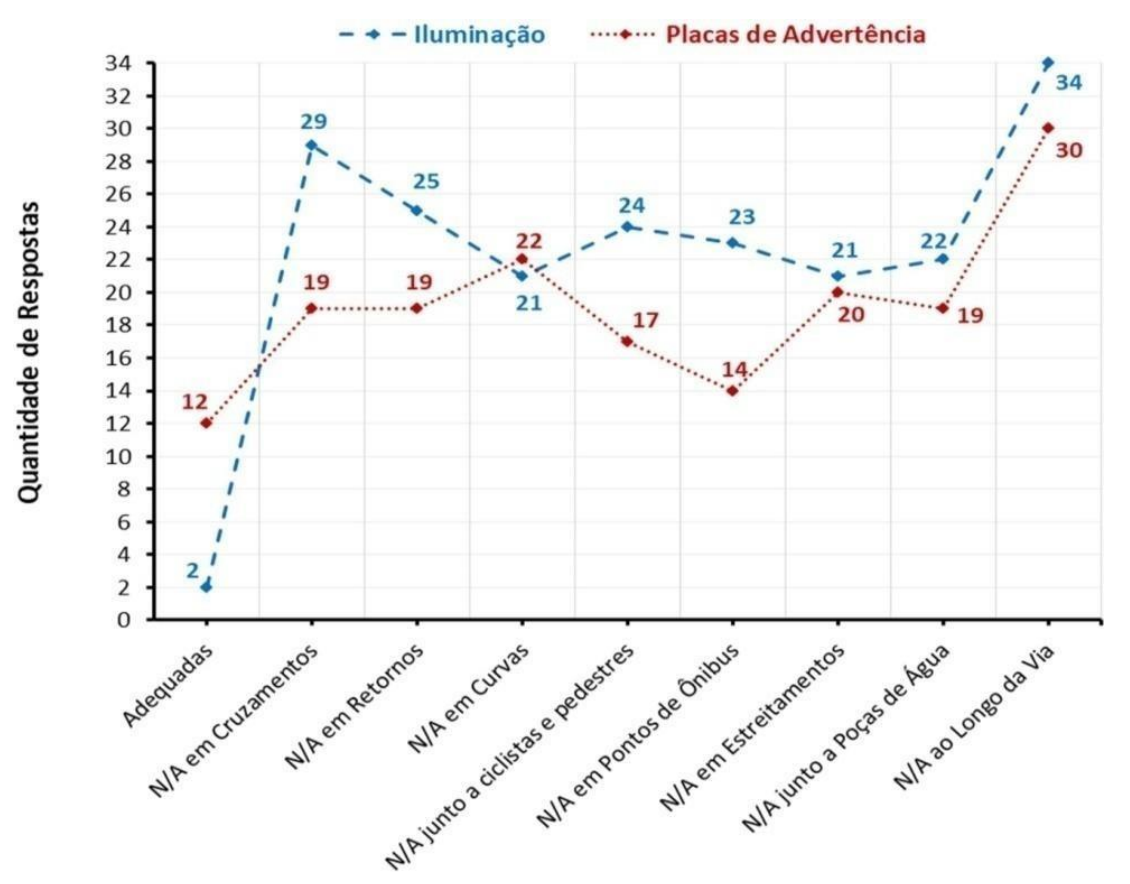

Fonte: Elaborado pelos autores. Nota: N/A - Não adequada 
Por fim, os participantes foram questionados quanto às condições dos pontos de ônibus situados ao longo da Linha Azul. A maioria dos entrevistados apontaram como falhas graves a falta de proteção oferecida pelas estruturas às intempéries e a alta exposição a assaltos (respectivamente $58 \%$ e 56\%). Aproximadamente $46 \%$ das respostas relataram que a quantidade de ônibus que guarnecem a região é pequena, o que, consequentemente, ocasiona longos tempos de espera, aumentando a exposição à riscos. As opções de falta de sinalização adequada e risco de atropelamento em conjunto, responderam por $37 \%$ das respostas. Apenas $2 \%$ dos entrevistados julgaram que os pontos de ônibus atuais são adequados ao uso. Vale recordar, que dentre todos os respondentes onze assinalaram fazer uso constante deste modal.

As respostas obtidas através do questionário evidenciaram pontos importantes para a avaliação e atuação dos agentes responsáveis, e podem orientar a formulação de políticas públicas, visando a promoção da segurança na via e atendimento das necessidades dos cidadãos.

\subsection{ANÁLISE DO LEVANTAMENTO EM CAMPO}

Nesta última etapa, visitou-se a via com o objetivo de identificar deficiências nos elementos físicos que a compõem e que possam vir a ser nocivos à segurança de seus usuários, além de verificar os fatores apontados na etapa de questionário online. Cabe destacar que a proposta desta etapa é a identificação preliminar destes elementos, realizados com o objetivo de sinalizar possíveis riscos e melhorias para o objeto de estudo. Desta forma, para a elaboração de projetos de engenharia e planos de ação visando a efetiva solução destes problemas, recomenda- se a realização de estudos específicos e detalhados.

As deficiências observadas foram classificadas em quatro categorias: sinalização permanente; infraestrutura e o desempenho do pavimento; infraestrutura para transporte ativo; e infraestrutura para transporte coletivo.

\subsubsection{Sinalização permanente}

Segundo o Manual de Sinalização Rodoviária (BRASIL, 2010), a sinalização permanente é composta por sinais em placas e painéis, marcas viárias e dispositivos auxiliares com a finalidade de controle de tráfego que, ao serem implantadas, ordenam, advertem e orientam os 
seus usuários. Por definição, a sinalização horizontal é definida como o conjunto de marcas, símbolos e legendas aplicados sobre o revestimento de uma rodovia (BRASIL, 2010). Já a sinalização vertical é estabelecida através de comunicação por meio de placas, painéis ou dispositivos auxiliares situados na posição vertical implantados à margem da via ou suspensos. Verificou-se ausência de sinalização horizontal em diversos trechos da via, tanto por não terem sido empregadas anteriormente, quanto decorrentes da ausência de manutenção das pinturas. Destaca-se, como exemplo, a ausência de marcas longitudinais que delimitam as faixas de tráfego e acostamentos, marcas de canalização para orientações dos fluxos em situações de mudança de alinhamento da via e retornos. A Figura 11, ilustra o trecho de saída da Linha Azul para a rotatória com a RJ-168 e Linha Verde, com ausência de marcas de delimitação das faixas e canalização (uma vez que há estreitamento da via).

Quanto à sinalização vertical, também foram observadas ausências e deficiências. Na Figura 11, observa-se a ausência de sinalização vertical indicando a presença de rotatória à frente e dos riscos inerentes dos conflitos de fluxos da via. Também se observou a necessidade de implantação de sinalização vertical ao longo da via a fim de reforçar a presença de riscos na via, tais como, animais, pedestres e ciclistas; indicação e distância dos retornos; alerta e orientação nas curvas, retornos e pontes.

Figura 11 - Trecho de saída da Linha Azul e acesso à rotatória com a RJ-168 e Linha Verde - ausência de sinalização adequada

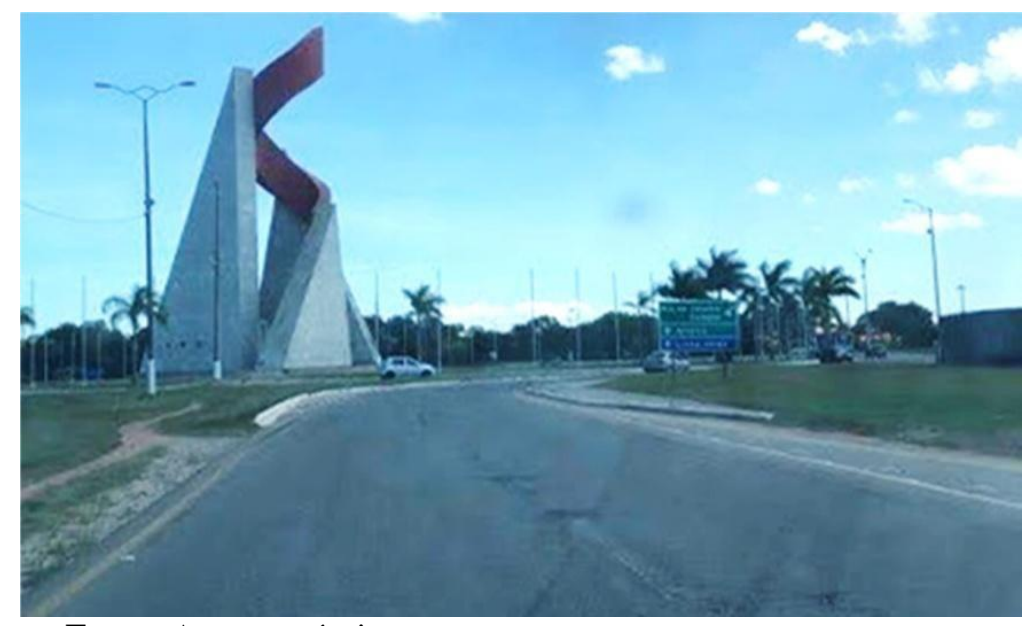

Fonte: Acervo próprio.

A presença de sinalização adequada está também atrelada à manutenção cuidadosa dos dispositivos danificados, para que seja visível e transmita a mensagem correta ao usuário, de 
forma que este tome suas decisões de forma segura. Verificou-se ao longo da via a necessidade de manutenção dos dispositivos de sinalização, tanto horizontal (nos casos em que as faixas se apagaram com o tempo), quanto vertical. A Figura 12 ilustra dois dispositivos verticais da via em estudo que necessitam de manutenção, tanto referente ao seu posicionamento e limpeza do terreno adjacente para retirada da vegetação, que está obstruindo sua visualização, quanto à inteligibilidade decorrente de pichação sobre a sinalização.

Figura 12 - Sinalização vertical prejudicadas, com necessidade de manutenção.
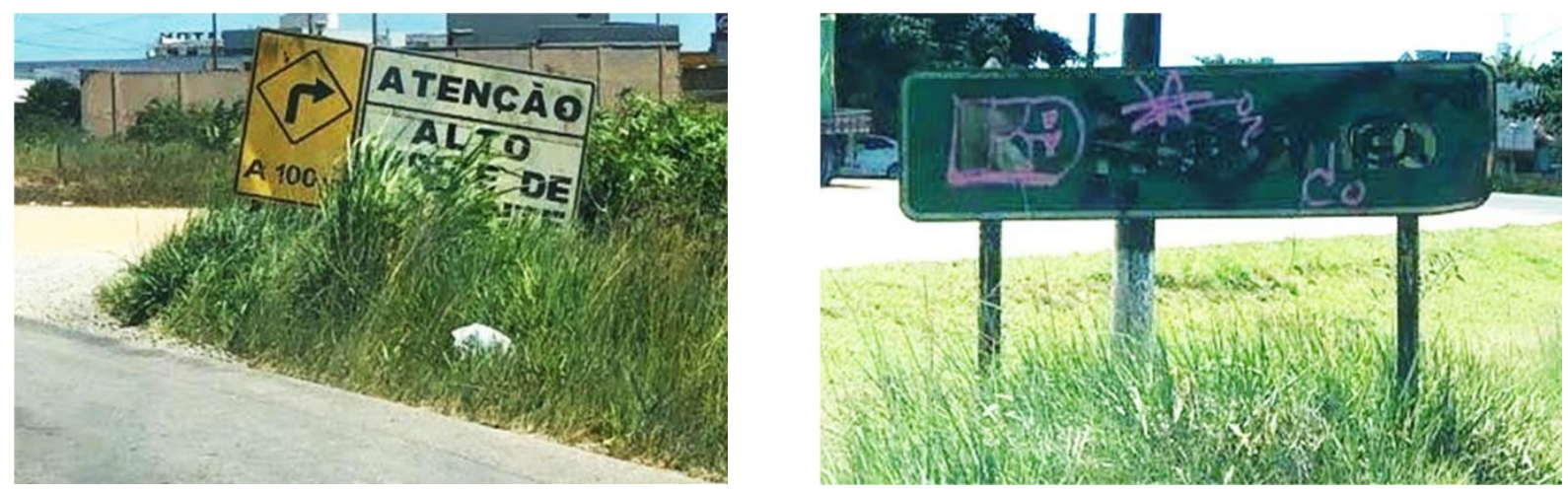

Fonte: Acervo próprio.

A ausência de sinalização permanente para orientação e regulamentação dos fluxos, somado à falta de fiscalização e a imprudência de alguns usuários, pode resultar em fluxos irregulares na via, que são causadores de acidentes. São observados, ao longo da Linha Azul, marcas de "retornos irregulares" sobre o canteiro central, realizados pela passagem dos veículos, como ilustrado na Figura 13. Cabe destacar que, durante as visitas ao local foram observados esses movimentos ilegais acontecendo em tempo real. Estas ocorrências são frequentes no trecho com maior registro de acidentes. Outro motivo que pode resultar nesses movimentos irregulares é a baixa densidade ou má localização dos retornos e cruzamentos, como, por exemplo, na entrada dos bairros existentes ao longo da via. Este cenário pode ser resultante da concepção inicial da via em estudo como Via de Trânsito Rápido. Assim, reforça-se a necessidade de ser repensada a infraestrutura da Linha Azul com base em sua real utilização, para adequá-la à sua atual e futura demanda. 
Figura 13 - Cruzamento irregular sobre o canteiro central.

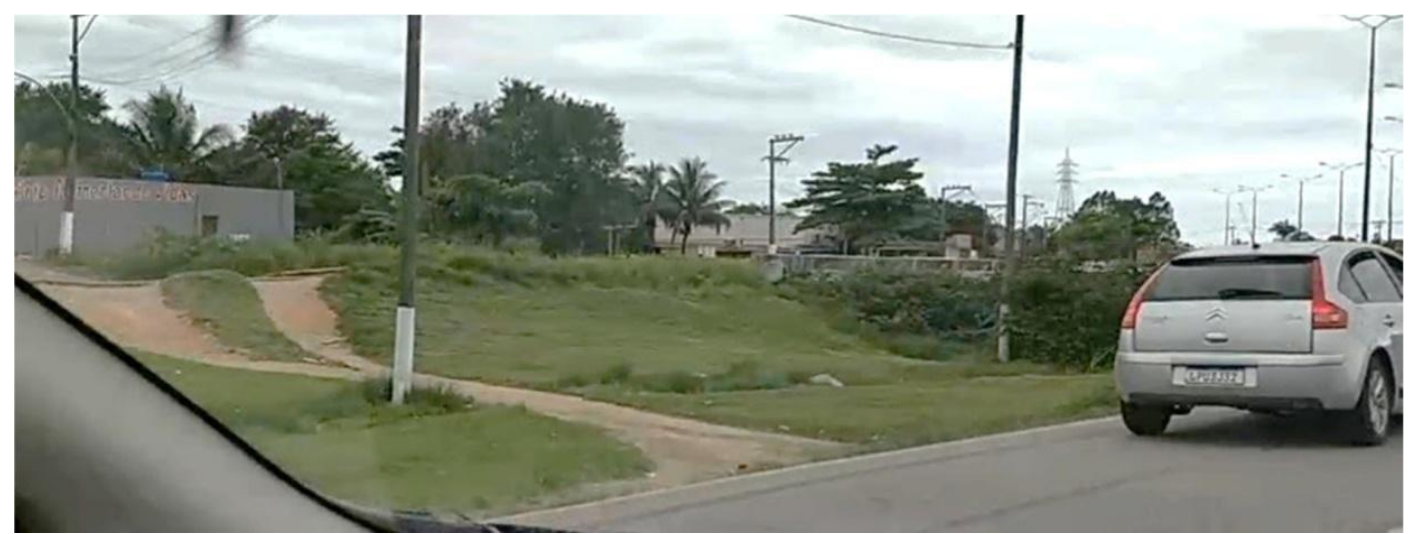

Fonte: Acervo próprio.

\subsubsection{Infraestrutura e desempenho do pavimento}

Por definição, o pavimento é a estrutura destinada a resistir e distribuir os esforços verticais e horizontais oriundos do tráfego, tornando mais durável a superfície de rolamento, além de melhorar as condições das faixas de rodagem quanto à segurança, comodidade e conforto aos usuários. Neste contexto, os pavimentos são avaliados de acordo com seu desempenho estrutural, funcional (superfície de serventia) e quanto à segurança.

Durante as visitas ao local, observou-se que diversos trechos da via apresentam defeitos e deteriorações, resultando em uma superfície de rolamento irregular e até incapaz de proporcionar conforto e segurança aos usuários. Foram notadas, em vários trechos, degradações superficiais e deformações em perfis, como: fissuras, trincas, trincas interligadas, desgaste (perda de agregado ou ligante), remendos, desnível entre a pista e o acostamento. A Figura 14, ilustra uma destas ocorrências.

Constatou-se que em trechos da via não há acostamento ou está deteriorado (Figura 14). O acostamento, além de permitir um espaço menos inseguro para o tráfego de transportes ativos e veículos por tração animal, auxilia também na proteção dos bordos da via contra a erosão. Recomenda-se, ainda, a presença de acostamento ao longo da via como área de escape para os veículos, uma vez que há grande volume de tráfego, alto índice de acidentes e presença de obstáculos ao longo do trecho estudado. 
Figura 14 - Pavimento com remendos, trincas e bordas erodidas, além da ausência de acostamento e desnível no bordo da via

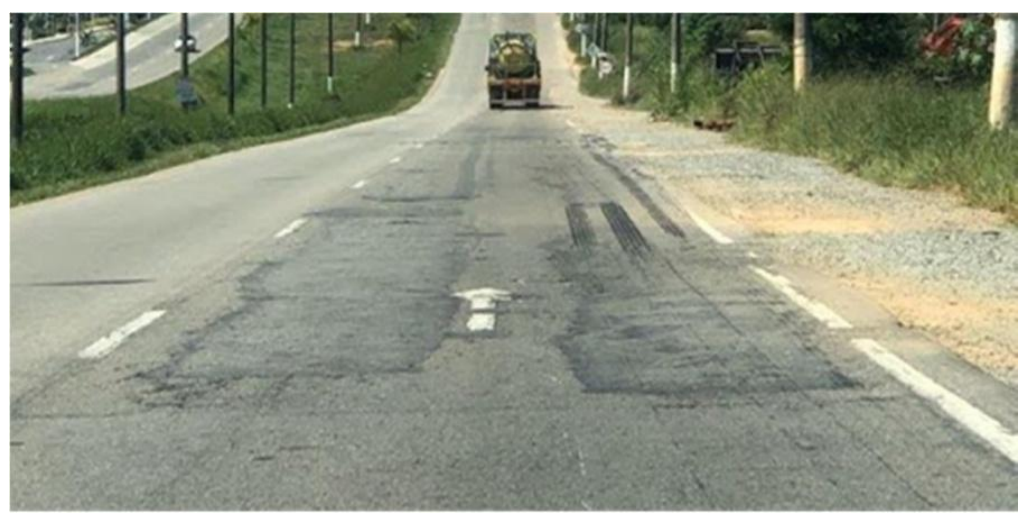

Fonte: Acervo próprio.

Além das irregularidades superficiais, observou-se marcas de frenagem ou derrapagem em diversos trechos ao longo da via, principalmente próximas à uma faixa de travessia de pedestres. Estas marcas indicam a falta de visibilidade dos motoristas na presença dos pedestres ou animais na via, exigindo frenagens abruptas, potencializando os riscos para o pedestre e motoristas, uma vez que pode resultar também em colisões traseiras.

A aderência entre pneu e pavimento é uma das características mais importantes em relação à segurança da via, fundamental para as ações de aceleração, desaceleração e mudança de direção sobre a superfície do pavimento. A diminuição do atrito é mais um fator que pode ser associado à ocorrência de acidentes. Neste contexto, destaca-se que foram observados depósitos de areia em vários pontos da via, inclusive em retornos, como ilustra a Figura 15. Ainda nesse contexto, verificou-se, em um levantamento em dia de chuva, o acúmulo de água sobre a via, validando as respostas obtidas por meio do questionário aplicado.

Figura 15 - Banco de areia próximo ao contorno da via e lâmina d'água em dia de chuva
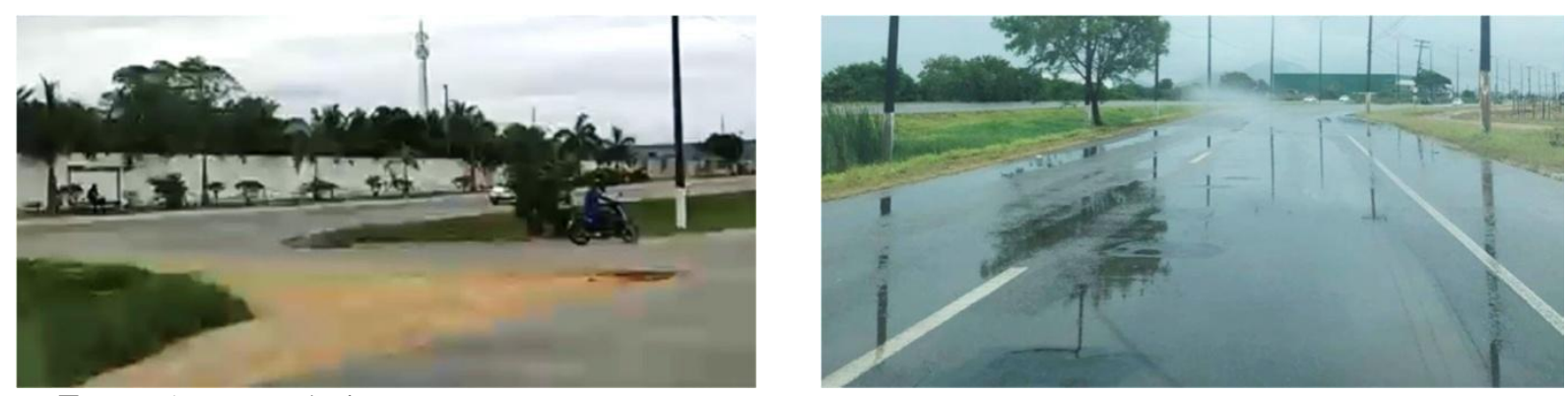

Fonte: Acervo próprio. 


\subsubsection{Infraestrutura para transporte ativo}

Conforme mencionado anteriormente, a Linha Azul foi planejada como Via de Trânsito Rápido, com características geométricas e estruturais destinadas à fluidez dos automotores, sem infraestrutura destinada aos transportes ativos (não-motorizados). Assim, a via não possui local apropriado para pedestres ou ciclistas, levando-os a compartilhar os espaços com os veículos automotores, o que culmina em grande risco de acidente, principalmente ao somar-se com a falta de sinalização, alta velocidade dos veículos e má iluminação (sinalizada pelo questionário aplicado aos usuários, mas não avaliada nesta etapa). A presença de pedestres e ciclistas na via destacada no questionário online foi confirmada durante as visitas ao local (Figura 16). Esta ocorrência é inevitável enquanto não houver infraestrutura específica e tende a ser crescente ao considerar as expansões e ocupações das regiões lindeiras da via a partir da exploração imobiliária.

Figura 16 - Ciclista e pedestres no acostamento da via.
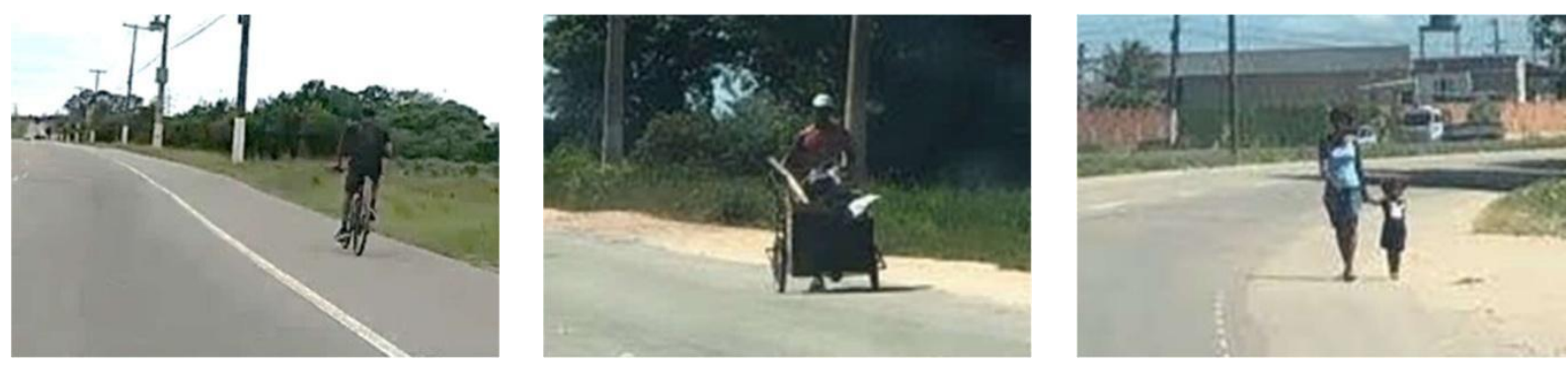

Fonte: Acervo próprio.

Ao longo dos 7,5 km de extensão, observou-se apenas dois locais para passagem de pedestres de um lado ao outro da via, distantes, aproximadamente, 6,3 km entre si. Esses locais são compostos por faixa de travessia de pedestres (sinalização horizontal) em nível, com a via associada a semáforos por acionamento, o que vai de encontro com a classificação atual da via. Observou-se que o semáforo estava inoperante, aumentando os riscos aos pedestres que necessitam cruzar as faixas de rodagem. A via também não possui dispositivos que promovam a acessibilidade e mobilidade de pessoas com deficiência - PcD. Observou-se a presença de rampa em apenas uma das travessias, porém fora dos padrões estabelecidos pela NBR 9050 - Acessibilidade a edificações, mobiliário, espaços e equipamentos urbanos (ABNT, 2004). 


\subsubsection{Infraestrutura para transporte coletivo}

A qualidade dos sistemas de transportes coletivos depende tanto da qualidade e tecnologia dos veículos utilizados, quanto dos locais adequados para a espera dos ônibus por parte dos passageiros. Na análise do questionário online, a opinião dos usuários da via quanto aos pontos de ônibus, resultou na indicação de que os pontos de ônibus não protegem os usuários do clima, não apresentam sinalização adequada, expõem os usuários aos riscos de atropelamento e assaltos. No levantamento em campo, pode-se observar que de fato não há estruturas adequadas nos pontos de ônibus, conforme Figura 17, e a maioria dos pontos de ônibus na Linha Azul são constituídos apenas por placas com a indicação do local, fixadas em postes às margens da via. Desta forma, verifica-se que não é fornecido conforto algum aos passageiros que aguardam a chegada dos ônibus, tanto pela falta de assentos, como de estruturas que os protejam das ameaças supracitadas. Os pontos devem possuir iluminação para aumentar a segurança dos usuários e, também, facilitar a visualização dos passageiros por parte dos motoristas. Em se tratando de uma via de trânsito rápido, recomenda-se, ainda, que o local de espera dos passageiros possua um recuo em relação às margens da pista, e seja munido de barreira física para proteger os pedestres em caso de acidentes.

Figura 17 - Ponto de ônibus na Linha Azul sem estrutura adequada.

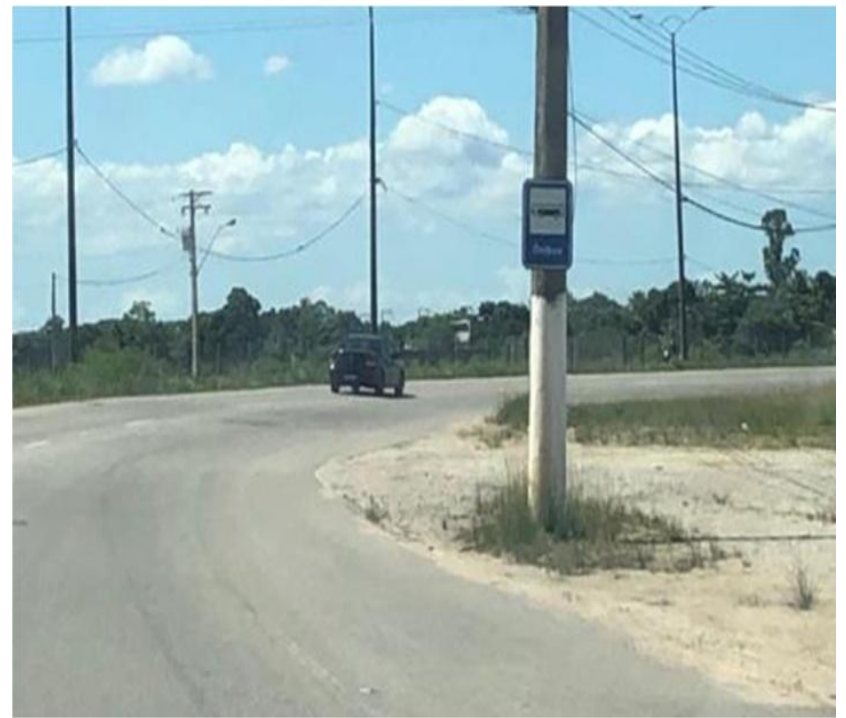

Fonte: Acervo próprio. 


\section{CONCLUSÕES}

A partir dos levantamentos e análises realizados neste trabalho, pode-se observar diversos fatores que influenciam as inseguranças enfrentadas pelos usuários da Linha Azul. Estes fatores, bem como destacado na literatura, são características físicas e comportamentais dos usuários, veículos (meios de transportes) e vias/ambientes. Tratando-se de uma via de trânsito rápido, com importante função logística para a mobilidade de Macaé e localizada em região da urbe com grande tendência de desenvolvimento nos arredores, recomenda-se o desenvolvimento de um plano estratégico de gerência para a via, destacando-se a manutenção preventiva dos equipamentos de sinalização permanente e dos dispositivos de drenagem, com acompanhamento para superar as devidas deficiências e as possíveis recorrências dos problemas que estão sendo apresentados neste trabalho.

A fiscalização, principalmente da velocidade operacional, é um ponto importante para a segurança da via. A implantação e ampliação do sistema de monitoramento e fiscalização, por meio de sistemas de videomonitoramento e radares, pode auxiliar no controle da velocidade dos veículos, fiscalizar a movimentação irregular de veículos (em sentidos opostos, por exemplo), e acompanhar da presença de animais na via para intervenção dos agentes responsáveis.

A partir das respostas que evidenciam tanto a presença de pedestres e bicicletas na via quanto a ausência de infraestrutura e sinalização para travessias adequadas, verifica-se a relevância da implantação de infraestrutura destinada aos transportes ativos, visando a acomodação da demanda existente. Cabe ressaltar que este ponto se faz ainda mais necessário ao considerar que o Plano Diretor Municipal permite a exploração imobiliária da região lindeira à via em estudo. Entretanto, não há no Plano de Mobilidade Urbana de Macaé, previsão de infraestrutura viária na Linha Azul, apontando também para a necessidade de atualização e adequação dos planos municipais para atendimento das necessidades da população de forma geral.

Outro problema agravante para a segurança do local é a falta de iluminação ao longo da via, principalmente em pontos cruciais (curvas, cruzamentos, retornos e locais com acúmulo de água). Este fator é primordial para a segurança, principalmente daqueles mais expostos, tais como pedestres e ciclistas. A implementação de um sistema de iluminação adequado, além de favorecer a segurança pública do local, associado às infraestruturas adequadas, pode incentivar o uso de 
transportes ativos e coletivos.

Segundo definições do PDM, as regiões lindeiras da via são destinadas a receber incentivos à promoção imobiliária residencial (principalmente para população de baixa e média renda), comercial e industrial, resultando em transformações socioeconômicas. Essas modificações exigiram adaptações com elementos de interrupção de fluxos não permitidos para a classe da via, como semáforos, faixas de pedestres e acessos diretos aos lotes lindeiros, prejudicando a segurança na trafegabilidade e sua operacionalidade. Uma vez que a dinâmica de transformação da urbe requer adaptações da infraestrutura da via em estudo, cabe a reflexão sobre a classificação atual da mesma e a possibilidade de uma transição, adequando-a às necessidades das populações lindeiras, sem que seu aspecto operacional seja prejudicado. Tem-se, então, a necessidade de um projeto que combata as inseguranças dos usuários da Linha Azul e que seja sustentável e inclusivo às pessoas com restrições de mobilidade. Com isso, após a análise crítica dos dados levantados, conclui-se que é de extrema importância e urgência que se formulem políticas públicas que contemplem ações preventivas e corretivas a serem implementadas na região, especialmente visando a adequação da via às suas características recentes de utilização, sendo algumas sugestões apresentadas neste trabalho.

Esta pesquisa está sujeita a algumas limitações que devem ser consideradas, e que podem servir de estímulo para trabalhos futuros. Primeiramente, a estrutura da pesquisa utilizada no questionário online fornece um instantâneo das opiniões deste grupo específico de participantes. Portanto, os resultados podem ou não representar toda a população de usuários da via. Sendo assim, os resultados encontram-se limitados em termos de tamanho da amostra. Uma população maior pode ser considerada em trabalhos futuros para superar esta questão. Além disso, outra limitação reside justamente no fato de que a proposta deste documento foi a identificação preliminar de elementos que influenciam na insegurança dos usuários da Linha Azul, com intuito de sinalizar alguns possíveis pontos de melhorias e riscos na via em estudo. Contudo, este não descarta a necessidade de uma investigação detalhada de cada tópico aqui abordado e que gere subsídios que viabilizem a elaboração de projetos de engenharia e planos de ação visando a solução dos problemas. Por fim, esta investigação pode ser propagada em inúmeras direções, entretanto, é sempre interessante analisar os aspectos técnicos em conjunto à avaliação da percepção daqueles que utilizam a via diariamente, uma vez que o usuário é capaz de obter uma compreensão refinada acerca dos riscos e ameaças aos quais está submetido. 


\section{REFERÊNCIAS}

AASHTO. Highway safety manual. Washington: American Association of State Highway and Transportation Officials, 2010.

ABNT. NBR 9050: acessibilidade a edificações, mobiliário, espaços e equipamentos urbanos. Rio de Janeiro: Associação Brasileira de Normas Técnicas, 2004.

BRASIL. Manual de sinalização rodoviária. Rio de Janeiro: Departamento Nacional de Infraestrutura de Transportes, 2010.

BRASIL. Lei no 012.587/2012: institui a Política Nacional de Mobilidade Urbana. Planalto, 2012.

CAMPOS, F. O fator humano e os acidentes de trânsito (primeira parte: visão geral). Arquivos Brasileiros de Psicologia Aplicada, v. 30, n. 3, p. 3-24, 1978.

CARVALHO, T.; GUIMARÃES, W., DELECAVE, J. Repercussões da exploração petrolífera sobre as transformações urbanas de Macaé (RJ). Cadernos do Desenvolvimento Fluminense, n. 1, fev. 2013.

DIAS, R. Instituições e desenvolvimento territorial: um estudo a partir do caso do arranjo produtivo de petróleo e gás natural localizado em Macaé-Brasil. EURE, v. 39, n. 116, p. 141-171, 2013.

GUIMARÃES, G. S. Comentários à lei de mobilidade urbana - Lei $\mathbf{n}^{0}$ 12.587/12: essencialidade, sustentabilidade, princípios e condicionantes do direito à mobilidade. Belo Horizonte: Fórum, 2012.

HOFFMAN, M. H. Comportamento do condutor e fenômenos psicológicos. Psicologia: Pesquisa \& Trânsito, v. 1, n. 1, p. 17-24, 2005.

MACAÉ. Lei complementar $\mathbf{n}^{\mathbf{0}}$ 076/2006: institui o Plano Diretor do Município de Macaé. Macaé: Prefeitura Municipal de Macaé, 2006.

MACAÉ. Decreto 30/2020: dispõe sobre a adoção de medidas preventiva para a contenção do coronavírus no Município de Macaé. Macaé: Prefeitura Municipal de Macaé, 2020.

RENUKAPPA, S.; AKINTOYE, A.; EGBU, C.; SURESH, S. Sustainable procurement strategies for competitive advantage: an empirical study. Proceedings of the Institution of Civil Engineers - Management, Procurement and Law, v. 169, n. 1, p. 17-25, 2016.

RESSIGUIER, J. H. B. Atividade petrolífera e impactos no espaço urbano do município de Macaé/RJ - 1970/2010. 113 f. Dissertação (Mestrado em Planejamento Regional e Gestão de Cidades), Universidade Cândido Mendes - Campos, 2011. 
RUPARATHNA, R.; HEWAGE, K. Sustainable procurement in the Canadian construction industry: current practices, drivers and opportunities. Journal of Cleaner Production, v. 109, p. 305-314, 2015.

\section{SARAGIOTTO, D. Mortes no trânsito: tráfego brasileiro mate 1 pessoa a cada 15 minutos.

Estadão, $2020 . \quad$ Disponível em:

https://mobilidade.estadao.com.br/mobilidade-com-seguranca/mortes-no-transito-brasileir omata-1-pessoa-a-cada-15-minutos

SAYD, J. L. C.; BRITTO, A. L. N. P. Estuário do Rio Macaé: O papel das obras hidráulicas na configuração do espaço urbano. In: Anais do XIV Seminário de História da Cidade e do Urbanismo, São Carlos, Brasil, 2016.

SINAY, M. C. F.; TAMAYO, A. S. Segurança viária: uma visão sistêmica. In: Rio de Transportes III, Rio de Janeiro, 2005.

TAMAYO, A. S. Procedimento para avaliação e análise da segurança de tráfego em vias expressas urbanas. Tese de Doutorado. Tese (Doutorado em Engenharia de Transportes), Universidade Federal do Rio de Janeiro. Rio de Janeiro, 2010.

UNITED NATIONS GENERAL ASSEMBLY. A/RES/74/299 Resolution adopted by the general assembly on 31 august 2020. 74/299. Improving global road safety. Disponível em: https:// https://undocs.org/en/A/RES/74/299.

WORLD HEALTH ORGANIZATION. Global status report on road safety 2018. Geneva: World Health Organization, 2018. Disponível em: http://who.int/publications/i/item/9789241565684. 